\title{
DIC TEXTURING-ASSISTED ACCELERATED SOLVENT EXTRACTION OF ACTIVE MOLECULES OF POMEGRANATE PEEL
}

\author{
Khaoula Elaydi, Ibtisam Kamal, Ahmed Bedoui, KarimAllaf
}

University of Gabes, Faculty of Sciences of Gabes, Erriadh City, 6072 Gabes, Tunisia

aydikhaoula@yahoo.fr

Soran University, Faculty of Engineering, Chemical Engineering Department, Kurdistan region -Iraq

ibtisamkamal@yahoo.fr

University of Gabes, Faculty of Sciences of Gabes, Erriadh City, 6072 Gabes, Tunisia

ahmed.bedouifsg@yahoo.fr

University of La Rochelle, Laboratory of Engineering Science for Environment LaSIEFRE-CNRS 3474, Avenue Michel Crepeau, 17042 La Rochelle cedex 01 (France).

karim.allaf@univ-Ir.fr

\begin{abstract}
The current work discusses the use of Instant Controlled Pressure Drop (DIC) as a pretreatment texturing stage intensifying phenolic compound extraction from South Tunisian Punica granatum L. peels in both cases of conventional and Accelerated Solvent Extraction (ASE). Response Surface Methodology (RSM) allowed identifying the effects of DIC processing parameters on the yields of Total Phenol Compounds (TPC), Total Flavonoid (TF), Condensed Tannins (CT), and Hydrolysable Tannins (HT), and antioxidant capacities via 2, 2-diphenyl-1-picrylhydrazyl (DPPH) radical-scavenging capacity and B-carotene-linoleic acid as responses. Comparative methods were used to evaluate DIC-textured and Raw samples. The results obtained confirmed that appropriate DIC-texturing improved both kinetic and yield of bioactive compound extraction using ASE from Punica granatum L. peels. Extraction kinetics was studied through Coupled Washing-Diffusion CWD model. The effective diffusivity was identified and quantified ranged from 0.27 to 8.22 against $0.4710^{-10} \mathrm{~m}^{2} \mathrm{~s}^{-1}$ for DIC textured and raw material (RM), respectively. DIC swelling enabled solid vegetal material matrix to expand and be more adapted to mass transfer thus increasing extractability of the phenol compounds. Scanning Electron Microscope SEM showed that DIC generated pores with an average diameter of $50 \mu \mathrm{m}$.
\end{abstract}

\section{INDEXING TERMS/KEYWORDS}

Punica granatum L. peels, Instant Controlled Pressure Drop (DIC), Accelerated Solvent Extraction (ASE), Response Surface Methodology (RSM), Extraction kinetics, Antioxidant activity.

\section{ACADEMIC DISCIPLINE AND SUB-DISCIPLINES}

Chemistry

\section{SUBJECTCLASSIFICATION}

Library of Congress ClassificationTP368-456 (Food Processing and Manufacture); TP155-15 (Chemical engineering)

\section{TYPE (METHOD/APPROACH)}

Experimental and phenomenological modeling

\section{Council for Innovative Research}

Peer Review Research Publishing System

\section{Journal: Journal of Advances in Chemistry}

Vol. 12, No. 2

editor@cirjac.com

www.cirjac.com 


\section{INRODUCTION}

The common name of Pomegranate (Punicagranatum L. Punicaceae) is derived from Latin words ponus and granatus), a seeded or granular apple, which is a delicious fruit consumed worldwide[1]. Pomegranate fruit is composed of three parts:seeds, juice, and peels [2].Several studies showed that pomegranate marc contains about $78 \%$ peels and $22 \%$ seeds on a wet basis [3-4]. Pomegranate peels PoPare characterized by an interior network of membranes comprising 26-30\% of total fruit weight and contained the almost quantity of phenolic compounds, including flavonoids (anthocyanins, catechins and other complex flavonoids), and condensed and hydrolysable tannins (gallic and ellagic acids, punicalin, pedunculagin, punicalagin, ).These compounds account about $92 \%$ of the antioxidant activity associated with the fruit[5-61].Thanks to its higher content of phenolic compounds, peels could be a good source of plant-based preservative agents in food industry [4].Previous studies indicated that pomegranate rind powder was investigatedas a bio-source of natural antioxidant in chicken patties[7]instead of the synthetic anti-oxidants such as BHT (butylated-hydroxytolune) orBHA (orbutylated-hydroxyanisole), which are suspected to be carcinogenic agents and their use in food industry are restricted. PoP contained also high nutrient substances such as, vitamins A, B6, C, E, folate, oxalic acid and high potassium content [8-9].Moreover, many studies indicated that the pomegranate is one of the oldest edible fruit, which has been used extensively in the folk medicine of many cultures [10-11].In addition, pomegranate rind has been exploited as natural source of dye[12].Tannins and flavonols are the two important coloring components of pomegranate rind and the main coloring agent is the Granatonine. This natural dye can replacesynthetic dyes, which are carcinogenic and highly toxic in nature[13].Other industrial uses of PoP include heavy metal removal[14], cosmetic beautification and enhancement, oral hygiene, weight loss soap[15] and microencapsulation phenolics[16].Due to its benefits, consume and production of pomegranate fruit have increased tremendously especially in the last decade. This natural and popular fruit is cultivated in numerous countries. The ancient sources of pomegranate are located in Iran, Pakistan, China and eastern India. However, the pomegranate cultivation is extended through the Mediterranean region to Turkish, European borders, American southwest and in African countries. In Tunisia, the pomegranate production is expected to reach 67,000 tons in 2013 for an area of 23, 000 hectares. The province of Gabes occupies the first place in terms of area and production with $63 \%$ of total production located in the coastal area of Gabes (South-East of the country)[17-18]. Nevertheless, in Tunisia, PoPare not sufficiently valorized and it is only exploited in some small traditional tanneries.

On the other hand, several scientific research work have been conducted on the extraction of polyphenols from PoP[319].Bioactive compounds extracted from peels were carried out with various organic and non-organic solvents using conventional and supercritical fluid extraction methods [3-19]. Methanol and acetone came up as suitable extraction solvents to reach good yields in the most of these researches. However, because of the environmental requirements of non-toxic food grade, only few numbers of organic solvents such as ethanol and n-butanol areaccepted by US Food and Drug Administration for extraction purposes [20].In this context, the factors affecting polyphenols extraction efficiency including the extraction methods, solvent type and concentration, temperature and time were investigated.

Accelerated Solvent Extraction (ASE) is one of the upcoming extraction techniques working at high temperature and pressure that can replace Soxhlet and other conventional and even intensified methods of solid-liquid interaction such as ultrasound and microwave-assisted extraction methods. It offers shorter operation time (15-30 min), more convenient and simplified manipulation and reduced solvent consumption (15- $50 \mathrm{ml} / \mathrm{g}$ solid). Since the natural structure of plants opposes resistance to penetration of any liquid, solvent extraction is highly time-consuming. So, to improve the release of bound phenolics from plants, manypretreatments process and procedures were testedsuch as enzymatic treatment[21], airdrying or freeze-drying [22]. Recently, the well-known texturing process of instant controlled pressure drop process DIC has been applied. This high temperature short time HTST treatment can couple structure expansion with preservation of heat sensitive compounds [23-24]. DIC pretreatment was applied to enhance the extraction yields of many polyphenols including flavonoids, tannins, anthocyanins as well as the essential oils from several plants such as orange peels [25], sumac barks [26], Tephrosiapurpurea seeds[27], etc.

In the present work, Gabes pomegranate peels PoP were studied with the objective to intensify the extraction of phenolic compounds in terms of availability and extractability, yields and kinetics. Since ASE was formerly optimized for pomegranate peel antioxidant extraction by Mustapha et al., [11] in terms of extraction temperature, particle size and static time.Our investigation aimed at comparing DIC-samples to the raw material.

\section{MATERIALS AND METHODS}

\section{Materials and reagents}

Tunisian pomegranates were purchased from Gabes local market. The peels were manually collected from fruits, rinsed with distilledwater, and then dried at room temperature $\left(25^{\circ} \mathrm{C}-28^{\circ} \mathrm{C}\right.$ for 20 days), to be treated by DIC. The DIC treated samples were then grounded and fractioned by a series of sieves $(0.85,0.425,0.25$ and $0.2 \mathrm{~mm})$, (Damavand Co., Iran) to obtain different particles sizes. The samples were then stored in refrigerator until analysis. The moisture content of peels pieces and powder was determined with the oven method by drying to a constant weight at $105^{\circ} \mathrm{C}$.

Folin-Ciocalteu reagent, Gallic acid, 2, 2-diphenyl-1-picrylhydrazyl(DPPH), B carotene, Linoleic acid, BHT (Butylatedhydroxytoluene), BHA (butylated hydroxyl anisole), Tween 40 (polyoxyethylenesorbitanmonopalmitate), Chloroform, Aluminum chloride, Potassium acetate, Quercetin, Catechin, Vanillin, Gallic and Tannic acids were purchased from Sigma-Aldrich Company(Saint Louis, MO, USA). Methanol and sodium carbonate $\left(\mathrm{Na}_{2} \mathrm{CO}_{3}\right)$ were obtained from 
Fisher Scientific Inc. (Pittsburgh, PA, USA). All the reagents were of analytical grade. Deionized water was produced by Millipore system (Millipore Corporation, USA).

\section{Instant Controlled Pressure Drop(DIC)}

Instant Controlled Pressure Drop(DIC) is a hydro-thermo-mechanical treatment able to texture, decontaminate, dry, etc. biological materials. The importance of DIC in different industrial sectors is due to its strong link with the intensification of many unit operations [28- 29]. DIC process is based on subjecting the raw material to saturated steam for a short period of time, followed by an abrupt pressure drop (about some dozens of milliseconds) towards a vacuum (about $5 \mathrm{kPa}$ ). This instant pressure drop provokes an autovaporization of a certain amount of water from the material, instantaneously cooling the products, stops thermal degradation, swells the plant matrix and possibly induces rupture of the cell walls. Final expanded structure is characterized by a high porosity and great specific surface area, which enhances mass transfer [27] through larger effective diffusivity of liquid within the material [28].

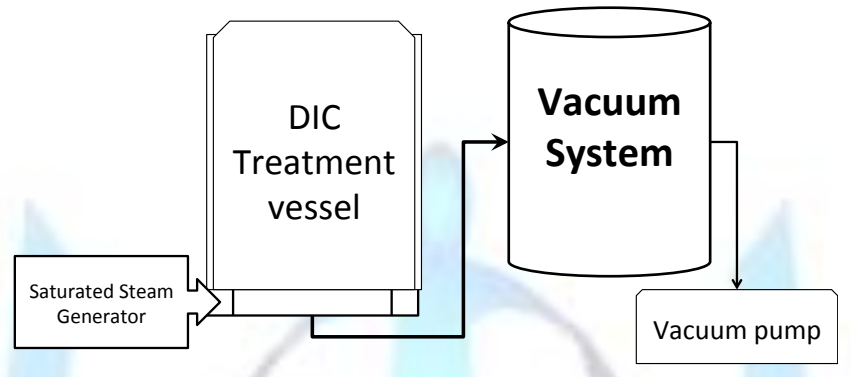

Figure 1.Scheme of lab-scale DIC equipment.

As detailed in numerous articles [30-31]), DIC equipment has three main parts: i) a high temperature/high pressureprocessing vessel, ii) a large vacuum tank and iii) an instantaneously opening large-section valve(Figure 1).Figure 2 shows the main steps of a DIC cycle.

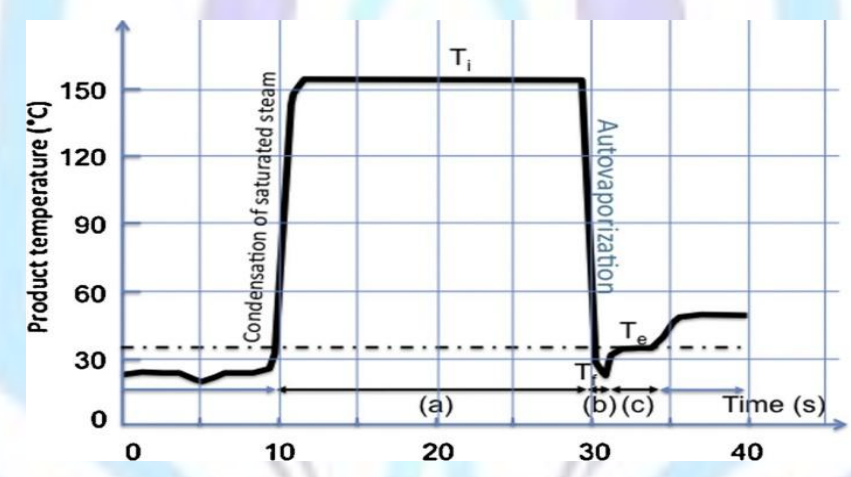

Figure 2. Temperature-time relationship in a DIC cycle: $T_{i}$ is the treatment temperature; $T_{e}$ the vacuum equilibrium temperature, a: the heating time, b: pressure drop time, c: vacuum time.

\section{Experimental Design}

After preliminary experimental trials, we selected the saturated steam pressure $(\mathrm{P})$ ranged between 0.24 and $0.46 \mathrm{MPa}$ and the thermal treatment time $(\mathrm{t})$ between 18 and 32s, as DIC operating independent parameters (Table 1). Through these DIC independent variables, a 2-parameter 5-level central composite rotatable Design of Experiments (DoE) was defined including $2^{2}=4$ factorial points, $2^{*} 2=4$ star-points and 5 repetitions of the central treatment point CTP.

Table1. Level of independent variables used in developing experimental data

\begin{tabular}{lccccc}
\hline Coded level & $-\alpha$ & -1 & 0 & +1 & $+\alpha$ \\
\hline Saturated Steam pressure (MPa) & 0.2 & 0.24 & 0.3 & 0.46 & 0.5 \\
\hline Processing time (s) & 15 & 18 & 30 & 32 & 35
\end{tabular}

Statgraphics for Windows software (5.1 version)was used to perform statistical analyses of variance (ANOVA) to determine if differences between the effects of independent variables weresignificant $(p<0.05)$.Pareto chart is introduced to identify the statistical significance of the independent variables on each response, with a vertical line showing if the effects are significant at 95\% confidence level. General trends analyze the behavior of each response versus factor changes. Surface response plot replicates the second-order polynomial empirical regression model and $R^{2}$ is used to accurate fitting models to real data. This allows identifying empirical second-order polynomial model of each dependent variable $Y$ (response)vsP and $t$, by fitting it with experimental data (Eq.1): 


$$
Y=\beta_{0}+\beta_{1} P+\beta_{2} t+\beta_{11} P^{2}+\beta_{22} t^{2}+\beta_{12} \mathrm{Pt}+\mathcal{E} \quad \text { Eq. } 1
$$

Where $\beta_{o}, \beta_{1}, \beta_{2}, \beta_{11}, \beta_{22}$, and $\beta_{12}$ are the regression coefficients, and $\mathcal{E}$ is the random error.In the specific studies of $\mathrm{DIC}$, if no significant effect of operating parameters is found, It is important to verify the possible relevant impact of texturing pretreatment by comparing the average of DIC-textured samples to the untreated sample.

\section{Accelerated Solvent Extraction (ASE)}

Accelerated Solvent Extraction system used in the present work, was ASE 350 equipped with a solvent controller unit from Dionex Corporation (Sunnyvale, CA, USA). $0.5 \mathrm{~g}$ ofdried powdered PoP with a particle size ranged from 65 to $212 \mu \mathrm{m}$ were placed in between two layers of diatomaceous earth in a $5 \mathrm{ml}$ Dionex (ASE 350) stainless-steel cell. The cells were equipped with a stainless steel frit and a cellulose filter $(20 \mu \mathrm{m}$ pore size; Dionex Corp.) at the bottom to avoid the collection of suspended particles in the collection vial. A dispersing agent (diatomaceous earth) was used to reduce the solvent volume required for the extraction. The $22 \mathrm{ml}$ stainless steel extraction cells and collection vials were loaded onto the automated carousel.

\section{ASE experiment}

Previous to each experiment an extraction cell heat-up was carried out for a given time of 5 minutes. The samples extracted were raw material and DIC-textured samples (Figure 3). Extraction procedure was as follows: i) sample is loaded into the extraction cell, ii), the cell is moved into the oven, once the oven temperature reached the set point $\left(40^{\circ} \mathrm{C}\right)$ and the pump filled the cell with solvent, iii) heat-up time is applied once the cell is preheated at $40^{\circ} \mathrm{C}$ for $5 \mathrm{~min}$, iv) $5 \mathrm{~min}$ static extraction step takes place in which all system valves are closed, $\mathrm{v}$ ) The extract was pumped into $60 \mathrm{ml}$ of collection vials and cell is rinsed with $60 \%$ of the cell volume using methanol solvent, vi) solvent is purged from cell with $\mathrm{N}_{2}$ gas and depressurization takes place. One extraction cycle was applied for all samples.Between two extractions, system was rinsed in order to overcome any carry-over. The extracts were protected from light and cold-stored until analysis.

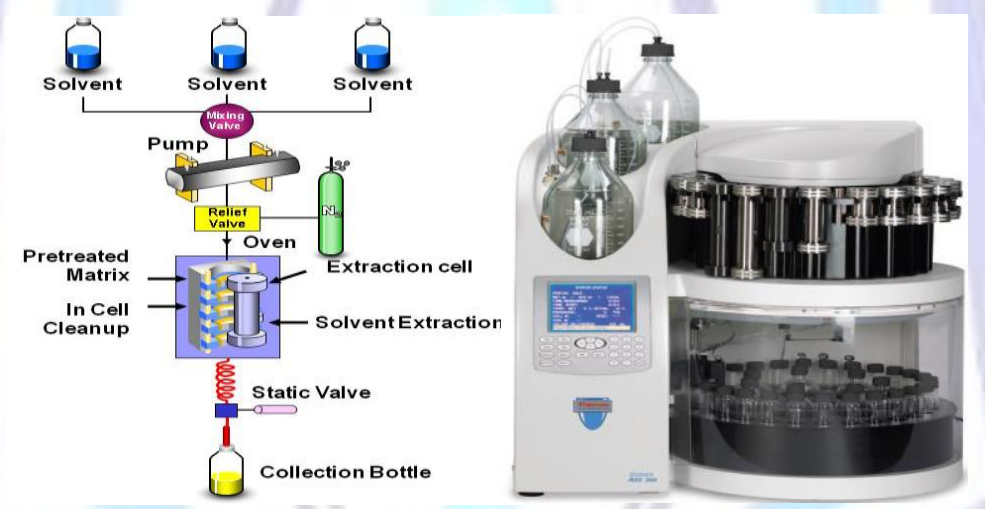

Figure 3.Thermo Scientific Dionex ASE 350 Accelerated Solvent Extractor system

\section{ASE parameters for pomegranate peels PoP}

It is worthy noting that ASE extraction preliminary experiments using water as solvent clogged with diamatous earth particles used as a dispersing agent. This stopped solvent penetration and obstructed extract passage. In this study, we used methanol as extraction solvent of PoP. This choice was founded on several motives. Indeed, methanol was selected in numerous studies as the perfect solvent for some classic (magnetic stirring extraction)and innovative (ultrasonicassisted)[19] extraction processes for pomegranate rinds plant. PoPPolyphenols have been extracted mostly by methanol or combinations of methanol and other organic[11]or inorganicsolvents (Subcritical fluid extraction SFE[32]).Moreover, due to its adequate polarity, PoP methanol extracts possess antioxidant activity higherthan other solvents [33-34-35]. Zahin showed that the methanol fraction had the highest antioxidant activity by four solvents in vitro assays comparable to ascorbic acid and butylatedhydroxy toluene (BHT) followed by ethanol, acetone, and ethyl acetate fractions[35]. ASE parameters we used for both cases of raw untextured and DIC-textured PoP were the same that of Mustapha et al. [11], with65-212 $\mu$ mas optimal particle size, $40{ }^{\circ} \mathrm{C}$ for $5 \mathrm{~min}$ as static time, which is the time required to assure interaction between sample and the extraction solvent. To ensure minimum solvent consumption, flush volume of $5 \%$ was selected as optimum for all experiments, which were performed with two extraction cycles; at the same pressure value (102.1 atm).

\section{Process analysis assay}

\section{Determination of Total Phenol Content (TPC)}

TPC was obtained using Folin-Ciocalteu (F-C) method according to Lapornik method [36]. Determination of total phenolic compounds was performed from the calibration curve obtained with Gallic acid used as standard. The results were 
expressed as milligrams of Gallic acid equivalents (GAE) per g of dry base (mg GAE/g db). Total phenols content values of the crude extracts of raw and DIC treated samples are tabulated in Table2.

\section{Determination ofTotal Flavonoid (TF) content}

According to Chang et al.[37]), aluminum chloride colorimetric method was used to determine TF content from PoP extracts. $0.5 \mathrm{ml}$ of 10 -fold diluted extracts was mixed with $1.5 \mathrm{ml}$ of methanol, $0.1 \mathrm{ml}$ of $10 \%$ aluminum chloride, $0.1 \mathrm{ml}$ of $1 \mathrm{M}$ potassium acetate and $2.8 \mathrm{ml}$ of distilled water. Then, it remained at room temperature for $30 \mathrm{~min}$. The absorbance of the reaction mixture was measured at $415 \mathrm{~nm}$. The calibration curve was prepared using Quercetin solutions at different concentrations. The level of the TF is expressed as milligrams of Quercetin equivalents per gram extract.

\section{Determination of Condensed tannins (CT)}

Various colorimetric methods[38] [39] were suggested to determine condensed tannins (CT).In the present work, CT was estimatedthrough Vanillin- $\mathrm{HCl}$ method described by Price et al. [40]. $1 \mathrm{ml}$ of methanolic samples solutions was mixed with $5 \mathrm{ml}$ vanillin solution $(0.5 \%)$ dissolved in methanol containing $4 \%$ of concentrated hydrochloric acid. After $20-\mathrm{min}$ incubation at $30^{\circ} \mathrm{C}$, the absorbance of reaction mixture was measured at $500 \mathrm{~nm}$. The same solution without vanillin was used as a blank. Catechin was the positive control in this assay. CT amounts from DIC-textured and raw material samples are given in Table 2 and expressed in $\mathrm{mg}$ Catech. $\mathrm{E} / \mathrm{g} \mathrm{db}$ (mg Catechin equivalent per $\mathrm{g}$ of dry basis of PoP).

\section{Determination of Hydrolysable tannins (HT)}

Hydrolysable tannins (HT) were determined followingWillis and Allen [41] method with slight modifications. $1 \mathrm{ml}$ of the diluted samples and $5 \mathrm{ml}$ of $\mathrm{KIO}_{3}$ aqueous solution $(2.5 \% \mathrm{w} / \mathrm{v})$ were added into a vial and vortexed for $10 \mathrm{~s}$. After $4 \mathrm{~min}$ additional tempering at $30^{\circ} \mathrm{C}$, absorbance values of extracts and standard solutions of tannic acid were measured at 550 $\mathrm{nm}$. Absorbance of the red colored mixtures formed was determined vs the prepared water blank. The analytical standard solutions of tannic acid $(0.5-2 \mathrm{~g} / \mathrm{l})$ were prepared by aqueous dilution. HT is expressed in mg tannic acid equivalent/g dry basis ( $m g$ TAE/g db).

\section{Measurements of antioxidants activities}

\section{2'-diphenyl-1-picrylhydrazyl (DPPH)radicalscavenging method}

PoP antioxidant activity was measured in terms of hydrogen donating or radical scavenging ability, using the stable radical DPPHaccording to the method reported by Brand-Williams et al. [42]with some modifications. An aliquot of $0.5 \mathrm{ml}$ of sample solution was mixed with $3 \mathrm{ml}$ of a $0.004 \%$ methanolic solution of DPPH. The sample solution was mixed thoroughly using a vortex mixer and incubated for $30 \mathrm{~min}$ in the dark at room temperature. The sample absorbance was measured at $517 \mathrm{~nm}$ using a UV-Vis spectro-photometer. The control is consisting in $0.5 \mathrm{ml}$ of methanol and $3 \mathrm{ml}$ of the DPPH solution $(0.004 \%)$. Results were expressed as percentage of inhibition of the DPPH radical. The remaining concentration of DPPH in the reaction medium was calculated with linear regression equation from a calibration curve. It needs to be taken into account that a very low value of absorbance of the reactant mixture indicates a high sequestrant capacity of free radicals (Inhibition \%), expressed numerically as:

$$
\text { Inhibition } \%=\frac{\mathrm{Abs}_{\mathrm{o}}-\mathrm{Abs}_{30 \mathrm{~min}}}{\mathrm{Abs}_{\mathrm{o}}}
$$

$A b s_{o}$ and $A b s_{30 \mathrm{~min}}$ are the absorbances of DPPH at time zero, and after $30 \mathrm{~min}$ of incubation, respectively. The percentages of remaining DPPH. were plotted against the sample or standard to obtain the amount of antioxidant necessary to reduce the initial concentration of DPPH.

\section{B- carotene-linoleate model system}

The antioxidant activities of the extracts, BHT and BHAsynthetic anti-oxidant were determined by a B-carotene-linoleate model system according to Singh method with slight modification [43]. Briefly, $0.2 \mathrm{mg}$ of B-carotene in $0.2 \mathrm{ml}$ chloroform, $20 \mathrm{mg}$ of linoleic acid, and $200 \mathrm{mg}$ of Tween-40 (polyoxyethylenesorbitanmonopalmitate) were mixed. Chloroform was removed in vacuum and nitrogen gas purging at $40^{\circ} \mathrm{C}$, and the mixture was diluted with $10 \mathrm{ml}$ of distilled water and mixed. Oxygenated water was added to this emulsion $40 \mathrm{ml} .4$ mlof this solution was transferred intoa vial containing $0.2 \mathrm{ml}$ of extracts diluted or synthetic anti-oxidant BHT with a concentration of $200 \mathrm{mg} / \mathrm{l}$, with different concentration ranges were prepared.The vials were placed in a thermostated water bath at $50{ }^{\circ} \mathrm{C}$. The absorbance of the solutions was measured at zero time $(t=0)$ and 15 min intervals until the color of $B$-Carotene disappeared in the control sample $(t=180$ min). Control sample was prepared in the same way using $0.2 \mathrm{ml}$ of methanol instead of extracts. Blank was prepared in the same way as explained above without using B-carotene. The anti-oxidant activity (AA\%) of the test samples was calculated in terms of bleaching of the $B$-carotene using the formula given below: 


$$
A A \%=\left[1-\left(\frac{A_{0}-A_{t}}{A_{0}^{0}-A_{t}^{0}}\right)\right] \quad \text { Eq. } 3
$$

Where $A_{0}, A_{0}^{0}, A_{t}$, and $A_{t}^{0}$ are the absorbance values of the test sample at zero time; the control sample at zero time; the test sample at $180 \mathrm{~min}$, and the control sample at $180 \mathrm{~min}$, respectively.

\section{Comparison of extraction performance}

Accelerated solvent extraction ASE was studied and compared with standard solvent extraction (SE) using identical extraction conditions: solid/liquid ratio $(0.5: 10 \mathrm{~g} / \mathrm{ml})$, particle size in the range from 65 to $212 \mu \mathrm{m}$ with total extraction time of $100 \mathrm{~min}$ at $40^{\circ} \mathrm{C}$. SE was aided by the use of an electric stirring device of $500 \mathrm{rpm}$. This extraction system was composed of a reactor, a bath boiler and a refrigerant. At intervals of determined times, $1 \mathrm{ml}$ of samples was syringed. The extracts were filtered through membrane filters $(45 \mu \mathrm{m})$ and analyzed with the same method mentioned above.

\section{Scanning Electron Microscopy (SEM)}

The ultra-structure of DIC-textured PoP samples was observed thanks to a scanning electron microscope SEM with Energy Dispersive X-Ray (SEM-EDX) (Nova Nano SEM 450). Measurements were carried out under partial vacuum and at an accelerating voltage of $25 \mathrm{kV}$, in Central Laboratory Unit, at Qatar University.

\section{RESULTS AND DISCUSSION}

The main results issued from ASE in the pure-methanol extraction of GabesPoP were collected in Table 2 for DIC-textured at various DIC operating parameters (independent variables) and untextured raw material (RM). They comprise yields of Total Phenolic Content (TPC), Hydrolysable Tannins (HT), Condensed Tannins (CT), and Total Flavonoids (TF) as responses and were used as dependent variables in a Central Composite Design.

Table 2. DIC operating parameters (independent variables) with, as responses (dependent variables): Total Phenolic Content (TPC), Hydrolysable Tannins (HT), Condensed Tannins (CT), Total Flavonoids (TF) yields, and antioxidant activity (AOA) in a Central Composite Design for pure-methanol ASE of Gabes pomegranate peels PoP.

\begin{tabular}{|c|c|c|c|c|c|c|c|c|c|c|}
\hline Trial no. & CPT & 2 & 3 & 5 & 6 & 8 & 9 & 11 & 12 & RM \\
\hline Pressure(MPa) & 0.35 & 0.50 & 0.35 & 0.46 & 0.46 & 0.24 & 0.24 & 0.20 & 0.35 & - \\
\hline Time(s) & 25 & 25 & 35 & 32 & 18 & 18 & 32 & 25 & 15 & - \\
\hline $\mathrm{TPC} \pm \mathrm{SD}$ (mg GAE/g db) & $232 \pm 6$ & $299 \pm 10$ & $234 \pm 4$ & $218 \pm 9$ & $261 \pm 9$ & $275 \pm 7$ & $237 \pm 6$ & $253 \pm 10$ & $250 \pm 10$ & $232 \pm 5$ \\
\hline $\mathrm{HT} \pm \mathrm{SD}$ (mg TAE/g db) & $510 \pm 8$ & $560 \pm 10$ & $515 \pm 9$ & $520 \pm 11$ & $520 \pm 10$ & $539 \pm 13$ & $511 \pm 13$ & $513 \pm 10$ & $491 \pm 11$ & $435 \pm 10$ \\
\hline $\mathrm{CT} \pm \mathrm{SD}$ (mg Cat.E/gdb) & $9.9 \pm 0.9$ & $11 \pm 1$ & $8.6 \pm 1.1$ & $10 \pm 1$ & $11 \pm 1$ & $11 \pm 1$ & $8.8 \pm 0.2$ & $7.4 \pm 0.6$ & $10 \pm 1$ & $9.3 \pm 0.8$ \\
\hline $\mathrm{TF} \pm \mathrm{SD}$ (mg Querc.E/gdb) & $17 \pm 2$ & $23 \pm 2$ & $19 \pm 2.5$ & $21 \pm 3$ & $19 \pm 3$ & $19 \pm 1.7$ & $18 \pm 2$ & $23 \pm 3$ & $20 \pm 3$ & $15 \pm 2$ \\
\hline Test DPPH (\% Inhibition) & $77 \pm 2$ & $81 \pm 2$ & $79 \pm 0.9$ & $77 \pm 1$ & $77 \pm 1.1$ & $79 \pm 1$ & $77 \pm 1$ & $78 \pm 1$ & $77 \pm 1$ & $74 \pm 2$ \\
\hline ß-carotene-linoleate (\%AA) & $77 \pm 2$ & $82 \pm 2$ & $77 \pm 1.2$ & $79 \pm 2$ & $80 \pm 1$ & $81 \pm 1$ & $77 \pm 2$ & $79 \pm 2.6$ & $76 \pm 2.8$ & $71 \pm 3$ \\
\hline
\end{tabular}

CPT: Centralized Point Treatment (DIC 1;4;7;10;13)

\section{Total phenolsContent TPC}

The total phenols extraction from PoP was optimized through the RSM approach. The results given from all runs as performed in Table 2 were reported in multiple linear regressions using the second-order polynomial model with DIC operating parameters ( $P$ and $t)$ as independent factors. It is remarkable that all TPC values from experimental tests for DIC-textured samples (ranged from 232 to $299 \mathrm{mg} \mathrm{GAE} / \mathrm{g} \mathrm{db}$ ) were systematically higher than the raw material RM (232 $\mathrm{mg} \mathrm{GAE} / \mathrm{g} \mathrm{db}$ ). This finding can be easily explained considering that DIC operating parameters positively affect the vegetal morphology resulting in higher availability of TPC. The significance of DIC operating parameters (pressure P and heating time t) on TPC extraction yields is estimated from the response surface analyses (Figure 4).

They indicate that $\mathrm{P}^{2}$ had a positive significant effect whereas $\mathrm{t}$ had a weaknegative influence. The statistical analysis gave a responsesurface described by the following regression equation whose correlation coefficientR ${ }^{2}$ of $68 \%$ :

$$
\text { TPC }=472-1031 P-3.40 t+1577 P^{2}-1.4 P t+0.04 t^{2} \quad \text { Eq. } 4
$$

The quadratic effect of DIC saturated steam pressure $\mathrm{P}$ on TPC yields means that by increasing $\mathrm{P}$ from 0.24 to $0.35 \mathrm{MPa}$, TPC yields decreased then from 0.35 to $0.46 \mathrm{MPa}$, it increased. The effect of pressure on TPC yields may be correlated with the presence of several types of phenols, monomeric and polymeric compounds in pomegranate rinds, which are known to be very rich in ellagitannins and gallotannins. Nine phenolic groups were identified as major components in 
pomegranate rinds [44-45] including flavonoids (anthocyanins, catechins and other complex flavonoids), condensed and hydrolysable tannins (punicalin, pedunculagin, punicalagin, and Gallic and ellagic acids). The evolution of TPC versus $P$ may be explained by a hydrothermal degradation of the long polyphenolic chains to small chains once steam invades the treatment vessel, oppositely coupled with increasing of TPC yields thanks to cell wall rupture due to high pressure-drop. The optimal value of TPC was estimated to be $301 \mathrm{mg} \mathrm{GAE} / \mathrm{g} \mathrm{db}$ at $\mathrm{P}=0.5 \mathrm{MPa}$ and $\mathrm{t}=15 \mathrm{~s}$. This means $130 \%$ higher than the untextured raw material. Comparing to the literature, the amount of TPC extracted from GabesPoP using DIC treatment was higher than those established by Amani (124.3 - $249.4 \mathrm{mg} \mathrm{GAE} / \mathrm{g}$ dry solids) [8] for extraction of PoP varieties from India and Kashmir district.
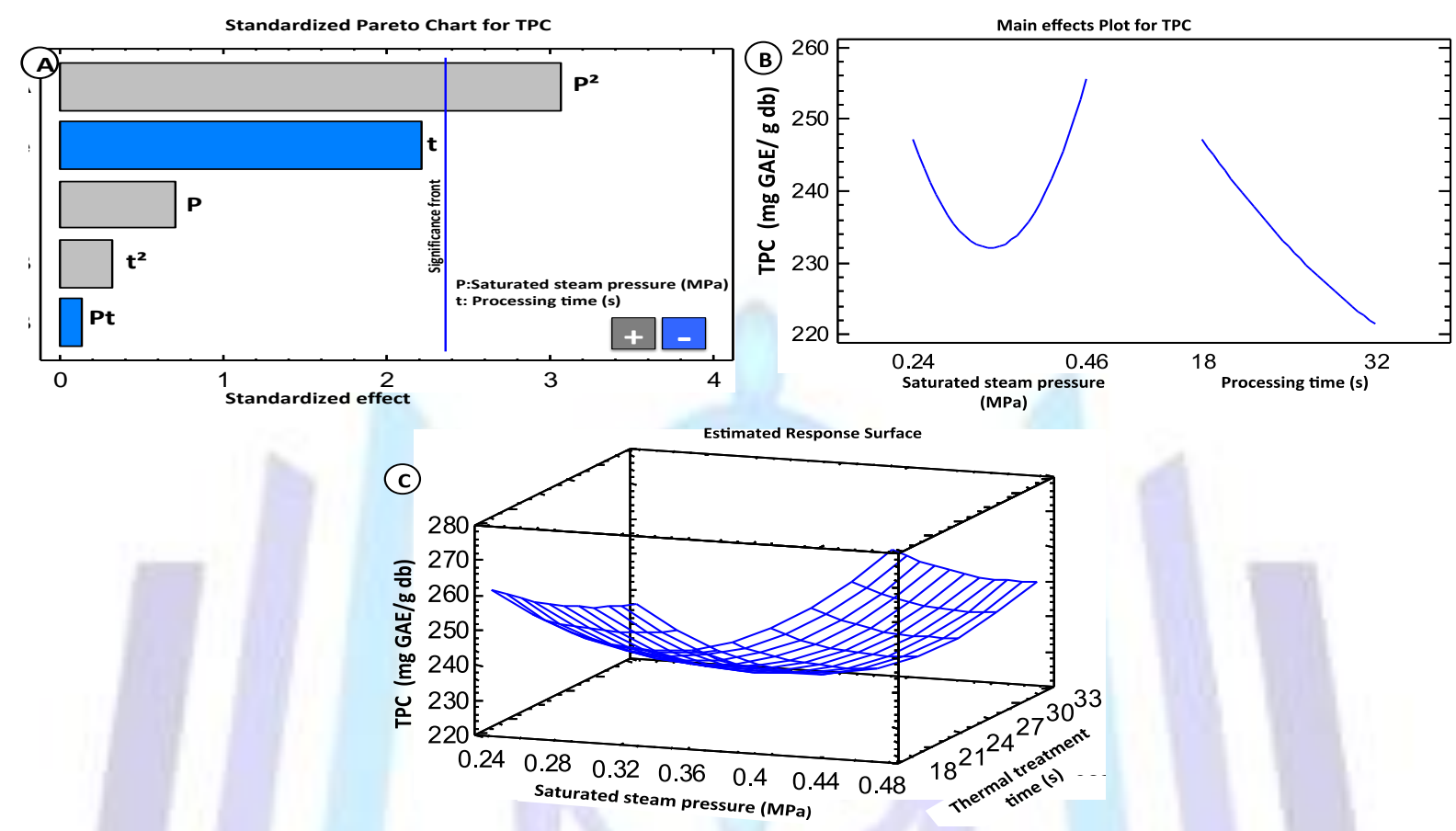

Figure 4. Pareto chart of DIC operating parameters (A), general trends (B), and response surface (C) for DIC treatment prior to ASE of pomegranate peel TPC extraction.

\section{RSA analysis of Hydrolysable tannins}

Pomegranate peel contains substantial amounts of polyphenols such as ellagic tannins, ellagic acid and Gallic acid. It has been used in the preparation of tinctures, cosmetics, therapeutic formulae and food recipes [6]. Increasing saturated steam pressure of DIC had a global positive effect on the extraction of bioactive molecules, after a first initial negative effect. Here too, some thermal degradation process would be coupled to a higher availability of tannins of DIC textured samples. 


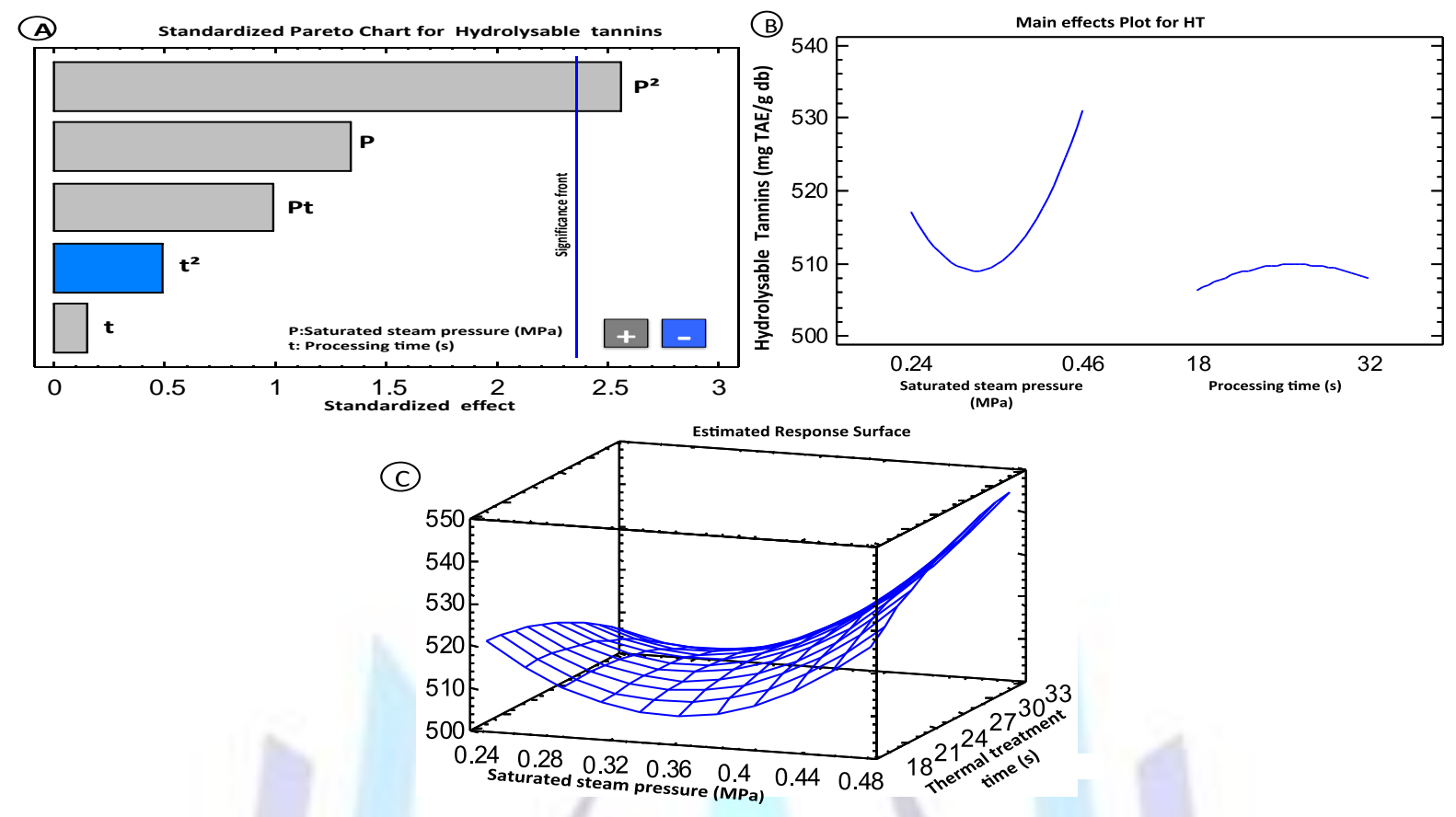

Figure 5. Pareto chart of DIC operating parameters (A), general trends (B), and response surface (C) for DIC treatment prior to ASE of Hydrolysable tannins of pomegranate peels PoP.

Regarding a possible tannin decomposition and extraction of other parasite products, low pressure extraction was recommended by Sriro [46]. Results from Table 2 indicate that the levels of hydrolysable tannins from DIC samples, which are ranged from 491 to $560 \mathrm{mg} \mathrm{TAE} / \mathrm{gdb}$, were systematically higher than those for control sample (435 $\pm 10 \mathrm{mg} \mathrm{TAE} / \mathrm{gdb})$. Moreover, HT yields were about 50 times higher than condensed tannin amounts.

These values are higher than the findings of Mustapha and al.[11] who studied Turkish PoP with hydrolysable tannins amount from 22 to 27 times higher than condensed tannins. The pomegranate age, the climatic/agro-environmental conditions could explain the change in the polyphenolic composition between different cultivars [9].

Figure 5 shows the effect of DIC operating parameters on HT extraction. Pareto chart (Figure $5 \mathrm{~A}$ ) shows that $\mathrm{P}^{2}$ has the main effect of DIC parameters for HT extraction while the thermal treatment time (t) seems not significant in the interval between 18 and 32s.

Main effects plots shown in Figure $5 \mathrm{~B}$, describe a slight decrease in the response from 520 to $500 \mathrm{mg}$ TAE/g db in the pressure range from 0.24 to $0.32 \mathrm{MPa}$. Then, $\mathrm{HT}$ amount increases to achieve a maximum of $550 \mathrm{mg}$ TAE/g db at steam pressure of $0.46 \mathrm{MPa}$. These fittings can be explained by the fact that tannin level is strongly linked to the pomegranate peel thickness according to Cardon et al. [47] and Chavan et al.[48].Thus, since DIC-treatment is known as a relevant texturing way of the solid matrix vegetable structure [49], although all samples were in the same average of particular size, the higher expansion and porosity of solid matrix gave higher yield of hydrolysable tannins. The empirical relationship between HT and DIC operating parameters is given in Eq.5.

$$
\mathbf{H T}=\mathbf{6 7 6}-992.2 \mathrm{P}-0.434 \mathrm{t}+\mathbf{1 1 7 1} \mathbf{P}^{2}+9.43 \mathrm{Pt}-0.055 \mathrm{t}^{2} \quad \text { Eq. } 5
$$

The optimum predictive value of $\mathrm{HT}$ was obtained at $\mathrm{P}=0.5 \mathrm{MPa}$ and $\mathrm{t}=35$ sto be $558 \mathrm{mg} \mathrm{TAE} / \mathrm{g}$ db against $435 \mathrm{mg}$ TAE/ $\mathrm{g}$ $\mathrm{db}$ for the raw material. DIC-textured samples had $128 \%$ increasing value in HT yield than untreated raw material.

\section{RSAanalysis of condensed tannins and total flavonoids from ASE}

Yield values of condensed tannins are shown in Table 2. It is remarkable that there is a slight increase in condensed tannin yields for some DIC samples compared to RM. The effect of DIC processing parameters on CT is shown in Figure 6. Pareto chart (Figure 6A) shows that steam pressure has the top most effect. $P$ affects positively CT response unlike the thermal treatment time. The positive effect of $P$ can be explained by the texturing effect of steam pressure-drop on the pomegranate peel structure, which should allow more availability of CT. Moreover, because tannins are highly soluble in water, heating time between 18 and $36 \mathrm{~s}$ had a negative effect on CT extraction yields. Thus, DIC treatment with a long time exceeding $18 \mathrm{~s}$ resulted in a loss or degradation of large condensed chains to more soluble small molecular units. The response surface of CT yields is presented in Figure $6 \mathrm{C}$. 

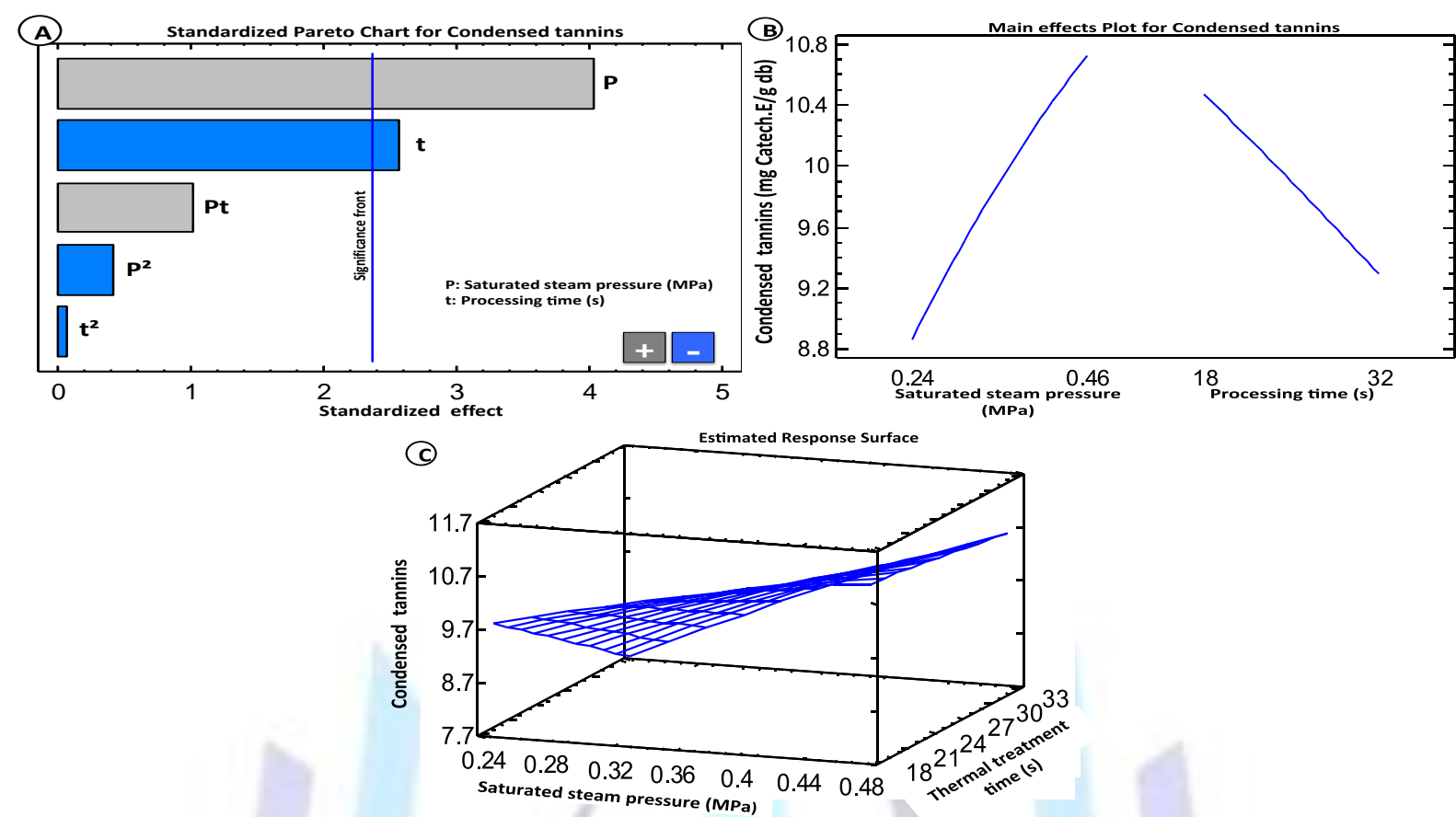

Figure 6. Pareto chart of DIC operating parameters (A), general trends (B), and response surface (C) for DICtexturing treatment prior to condensed tannins extraction from pomegranate peels PoP

The polynomial equation (Eq.6) estimated from RSA reflected the empirical model obtained with a satisfying coefficient $\left(\mathrm{R}^{2}\right.$ $=77.44 \%$ :

$$
\mathbf{C T}=\mathbf{1 1 . 5 6}+\mathbf{3 . 6 0 P}-\mathbf{0 . 2 1 7 t}-8.5 \mathrm{P}^{2}+0.43 \mathrm{Pt}-0,00037 \mathrm{t}^{2}
$$

Eq. 6

An optimum of CT value of 11.13 was obtained at $P=0.5 \mathrm{MPa}$ and $t=15 \mathrm{~s}$. Thus, CT yield of treated PoP was $120 \%$ higher than that of the untreated raw material. The functionality of condensed tannins highly depends on their structure in particular the degree of polymerization. Jerez and his contributors [50] confirmed that an increase in the antiradical power is observed with an increase in the degree of polymerization up to seven.

Flavonoids are polyphenolic compounds that are secondary metabolites exclusively from vegetal origin. The results of total flavonoid content (TF) for all runs are reported in multiple linear regressions using the second-order polynomial model were performed from the results of Table 2. It is well noticed that all TF responses from DIC samples were higher than the RM. TF values ranged between 17.47 to $22.8 \mathrm{mg}$ Querc.E/g db, against $15.40 \mathrm{mg}$ Querc.E/g db for the control. Pareto chart shows that $P^{2}$ has significant effect for TF extraction. However, the thermal treatment time effect was not significant for TF(Figure 7A).By applying multiple regression analysis on the experimental data, the response variable of flavonoid yields versus the independent variables was related by the following second-order polynomial equation (Eq.7). The model was satisfied with a regression factor $R^{2}=78.22 \%$ :

$$
\mathbf{T F}=\mathbf{5 2 . 4 1 0 4}-137.02 \mathrm{P}-0.90 \mathrm{t}+\mathbf{1 7 8 . 2} \mathbf{P}^{2}+0.63 \mathrm{Pt}+0.0130 \mathrm{t}^{2} \quad \text { Eq. } 7
$$

The effect of pressure on flavonoids extraction yield was found to be similar to that for TPC and condensed tannins CT. The negative effect of processing time on TPC and CT yield can be explained by the transformation of a main portion of polymeric condensed tannins with large molecular weights into other small units which are the flavonoids. This explanation can be justified by the optimum operating conditions of DIC derived from the model ( $P=0.5 \mathrm{MPa}$ and $t=15 \mathrm{~s})$ for both TPC and CT, .P remains optimal even in the case of TF; however, in the defined range, the thermal treatment time t effect was not significant as shown in Figure7B.

The benefic effect of DIC reveals in the optimal amount of TF (24.32 mg Querc.E / $\mathrm{g} \mathrm{db}$ ) given by the model under a steam pressure of $0.5 \mathrm{MPa}$ and thermal treatment time of $35 \mathrm{~s}$. The yield represents $158 \%$ more than that found from Raw Material. These results indicated that DIC-texturing pretreatment resulted in increasing the yield of bioactive molecules extraction compared to the untreated material. This may be attributed to the fact that DIC treatment causes structural modification and possible rupture of cell walls in the plant. 
(A)

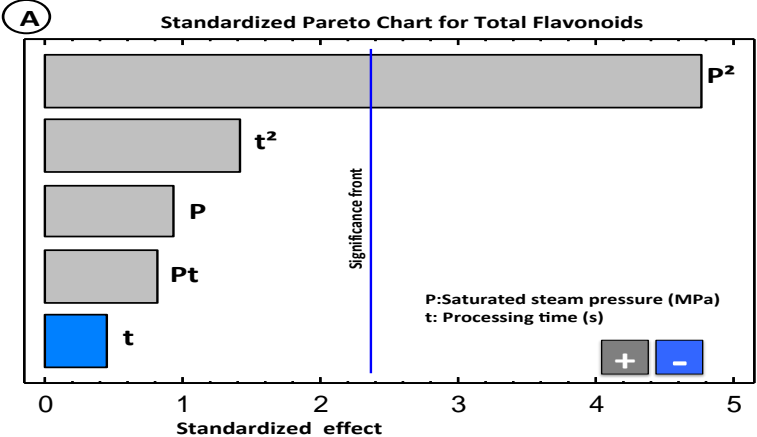

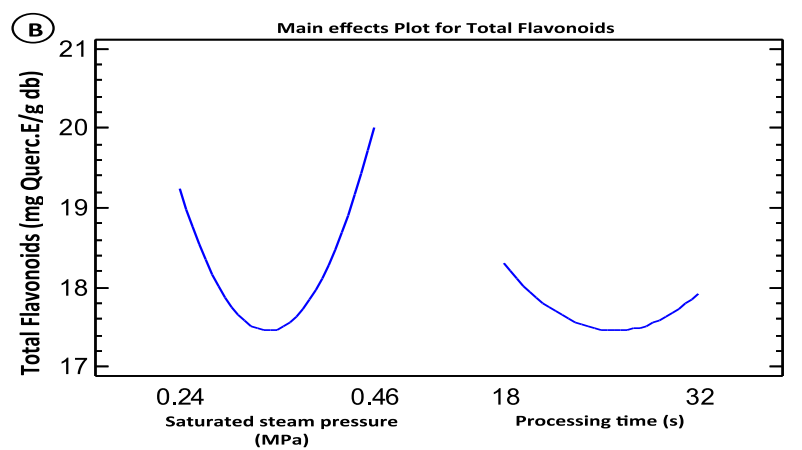

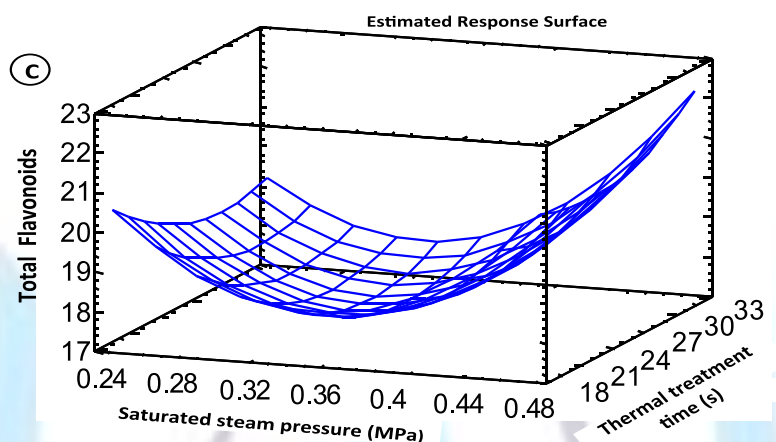

Figure 7. Pareto chart of DIC operating parameters (A), general trends (B), and response surface (C) for DIC treatment prior to Total Flavonoids extraction from pomegranate peels PoP.

\section{Antioxidant activity AOA}

Antioxidants are defined as compounds that can delay, inhibit, or prevent material oxidation by scavenging free radicals. Thus, they avoid the development of some chronic degenerative diseases including coronary heart illness, cancer, and aging [51].They are often divided into two general groups: Primary antioxidants, which act as free-radical scavengers to inhibit interrupt or prevent oxidation reactions; and secondary antioxidants, which react with hydro-peroxide groups to convert them to non-radical products [52]. Rind is the richest in antioxidants compounds part of pomegranate. The antioxidant activity AOA of all peels was evaluated using two methods;DPPH radical scavenging method and B-carotenelinoleate model system. The results of AOAare shown in Table 2.

From Table 2, it can be observed that all peel extracts had an important antioxidant capacity. The inhibition percentages of DIC-textured samples were ranged between $76.62 \%$ and $81.47 \%$ compared to $73.92 \%$ for the control. The effects of DIC operating parameters $(P$ and $t)$ in Inhibition \% are shown in Figure 8. Pareto chart results suggest that only $P^{2}$ had a significant effect. The empirical prediction model of inhibition \%related to DIC processing parameters is as follows with $\mathrm{R}^{2}=$ $60 \%$ :

$$
\text { Inhibition } \%=101.62-92.8 \mathrm{P}-0.824+\mathbf{1 1 5} \mathrm{P}^{2}+0.67 \mathrm{Pt}+0.012 \mathrm{t}^{2} \quad \text { Eq. } 8
$$

Response surface for inhibition\% indicated a maximum of $82.23 \%$ for $\mathrm{P}=0.5 \mathrm{MPa}$ and $\mathrm{t}=35 \mathrm{~s}$. This level is higher than that found for the control (73.92\%). In DPPH assay, antioxidant reacts with DPPH, which is a stable free radical, and convert it to $\alpha$, $\alpha$-diphenyl-ß-picryl hydrazine. The degree of discoloration indicates the scavenging potentials of the antioxidant extract[43].The high values of antioxidant would be due to the variability of phenolic compounds in all extracts. At 200 ppm, methanolic solutions from DIC6 textured and RM samples exhibited about $80 \%$ and $74 \%$ free radical scavenging activity, respectively, compared to $80 \%$ for BHT synthetic antioxidant with a concentration of $50 \mathrm{mg} / \mathrm{l}$.

The antioxidant activity of pomegranate peel extracts measured by the bleaching of B-carotene method is presented in Figure 9.The mechanism of bleaching of $B$-carotene is a free radical mediated phenomenon resulting from the hydroperoxides formed from linoleic acid [43]. The linoleic acid free radical attacks the highly unsaturated $B$-carotene models. The presence of different antioxidants can hinder the extent of $B$-carotene-bleaching by neutralizing the linoleatefree radical and other free radicals formed in the system[53]). As B-carotene molecules lose their double bonds by oxidation, the compound loses its chromophore and characteristic orange color, which can be monitored spectrophotometrically. In the absence of an antioxidant, B-carotene undergoes a rapid discoloration. Accordingly, the absorbance decreased rapidly in samples without antioxidant whereas, in the presence of an antioxidant, they retained their color, and thus absorbance, for longer time [54]. 

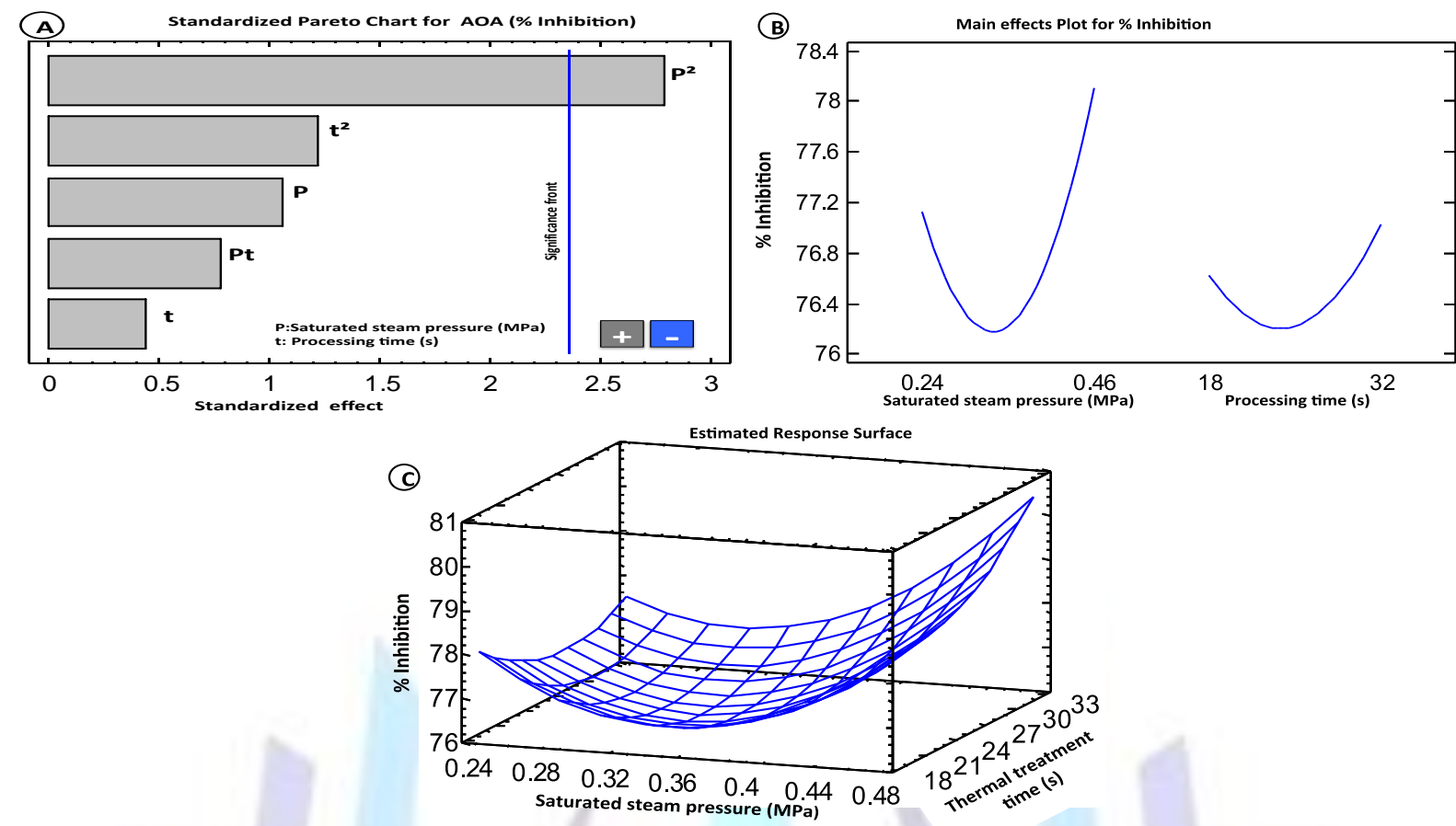

Figure 8. Pareto chart of DIC operating parameters (A), general trends (B), and response surface (C) for DIC treatment prior to \% Inhibition using DPPH in the extraction of PoP.

Pareto chart of DIC operating parameters, general trends and response surface for DIC treatment samples prior to \% AA extraction from PoP are shown in Figure 9. $\mathrm{P}^{2}$ had also the most significant effect while the thermal treatment time seemed not significant. The polynomial equation (Eq.9) estimated from RSA reflected the empirical model obtained with relatively satisfying $R^{2}$ value $(65.20 \%)$ :

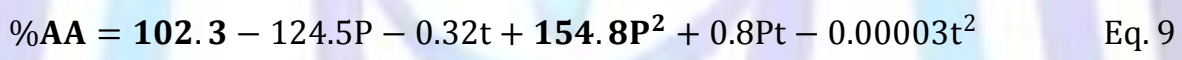

The optimum predictive values for antioxidant extracted from DIC-textured peels of Punicagranatum L. was $81.50 \%$ corresponding to $82.49 \%$ as estimated from the experimental results compared to $71.06 \%$ for the untreated raw material as shown in Table 2.
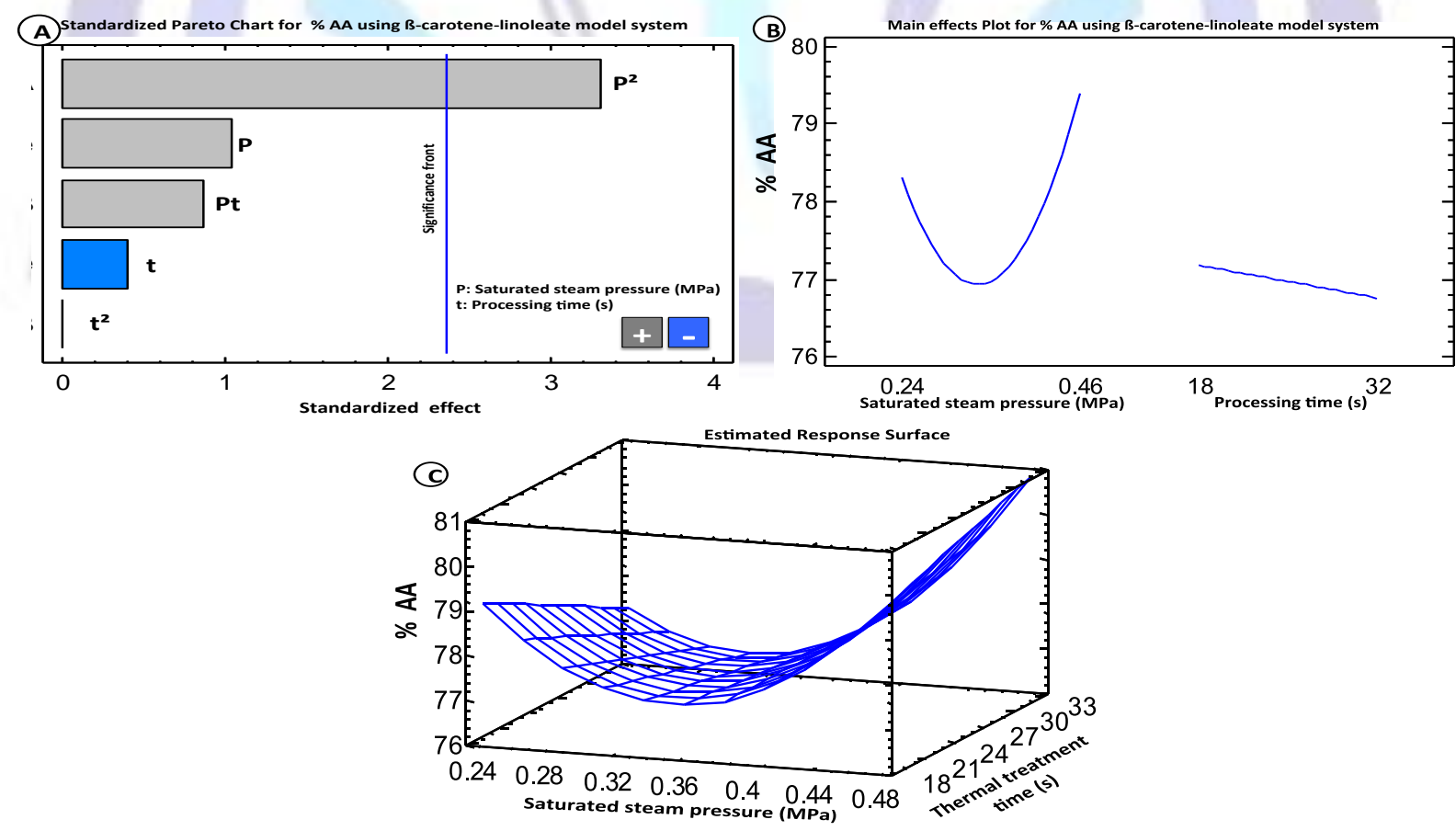

Figure 9. Pareto chart of DIC operating parameters (A), general trends (B), and response surface (C) for DIC treatment prior to \% AA using B carotene -linoleate model system from pomegranate peels PoP. 
Compared to synthetic antioxidants, Figure 10 shows that the average of \%AA of 200 ppm concentration solution of methanol ASE extracts of DIC-textured samples was higher than that of several concentrations of synthetic anti-oxidants such as BHA at 50 and $100 \mathrm{ppm}$, also, slightly superior to BHT at $50 \mathrm{ppm}$. Moreover, solutions of $100 \mathrm{ppm}$ BHT, DICtextured, and RM samples exhibited decreasing antioxidant activities, respectively. It is also remarkable to show that extracts of DIC 2 and RM samples exhibited about $81.50 \%$ and $71 \%$ antioxidant activity, respectively. This implicates an improvement of about $15 \%$ using DIC pretreatment. As a conclusion, it is important to note that antioxidant activity of all extracts were roughly two times more than $100 \mathrm{ppm}$ BHA and four times more than $50 \mathrm{ppm}$ BHT solution. Our study results had higher $A A \%$ values than that found in the literature [43-11].

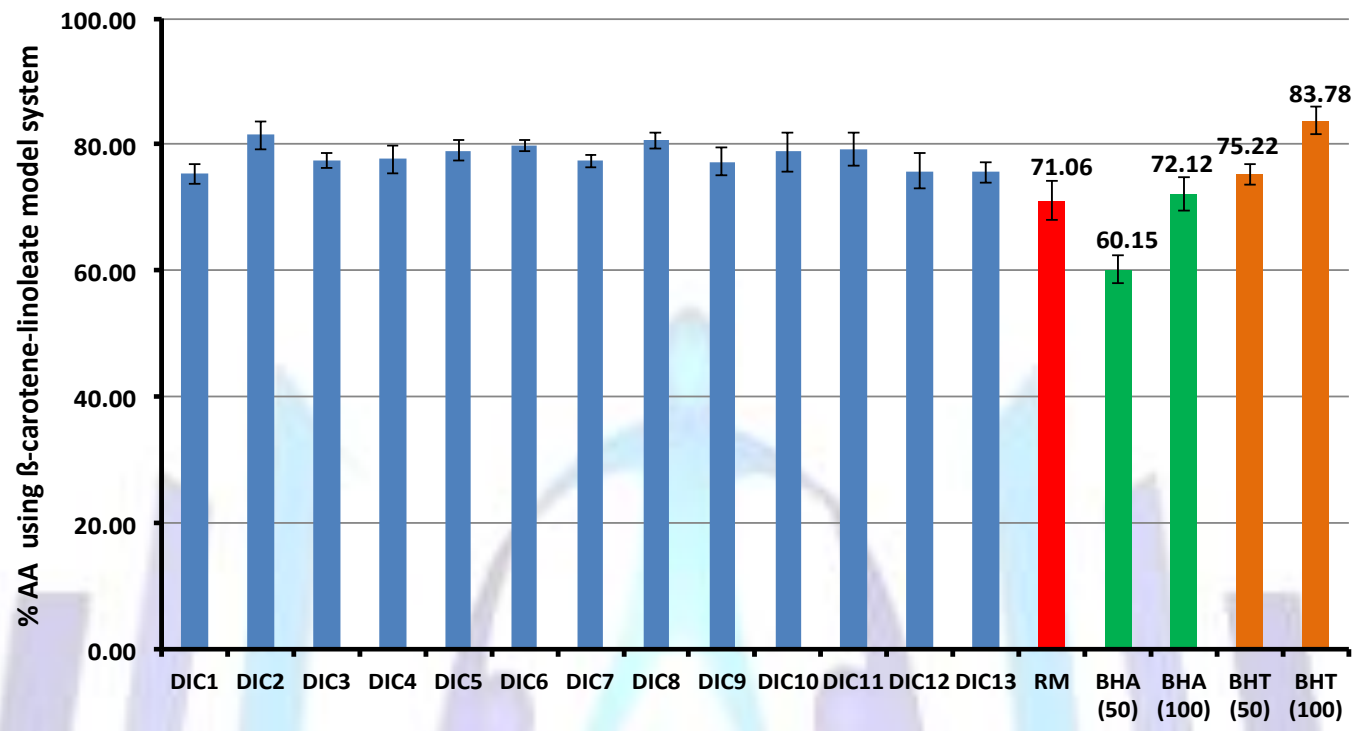

Figure10. Antioxidant activity (\%AA) of ASE extracts from DIC-textured and RM samles, natural and synthetic anti-oxidants of B-carotene-linoleate model system. (Bars show means $\pm S D$ of three replicates; (100), (50) means concentration (ppm).

PoP antioxidant activity is associated to phenolic compounds of anthocyanins, gallotannins, ellagitannins, dihydroflavonol, and hydroxybenzoic/ hydroxycinnamic acids [1]. Literature reported that $13 \% \mathrm{w} / \mathrm{w}$ PoP contains $10-50 \mathrm{mg} / 100 \mathrm{~g}$ as ellagic acid (monomer unit of hydrolysable tannins) [55], and 1.1-2 g/100 g peel powder as punicalagin ellagitanins [1].These studies demonstrated that punicalagin and ellagic acid have antioxidant, antifungal and antibacterial properties. Higher PoP antioxidant activity are directly associated with ellagic acid and punicalagin concentrations. PoP ellagitannins account for approximately $92 \%$ of the total antioxidant activity of pomegranate fruit [45].Thus, PoP powder was used as natural anti-oxidant source in chicken patties [7].

\section{Accelerated solvent extraction (ASE) vs Standard solvent extraction (SE)}

A quite comparative study describing the use of DIC-texturing pretreatment throughout two types of extraction methods and its effect on polyphenols yields is documented in this paragraph. Values of TPC, TF, CT, HT yields and antioxidant activity (\% inhibition) for raw and DIC2-textured POP samples using both conventional standard solvent extraction (dynamic extraction for $100 \mathrm{~min}$ at $40^{\circ} \mathrm{C}$ with $500 \mathrm{rpm}$ ) and ASE extraction method are summarized in Table 3 . The choice of DIC2 is essentially based on the maximum extraction yields of secondary metabolites.

Table3. ASE vs SE results of raw material RM and DIC-textured PoP

\begin{tabular}{c|c|c|c|c|c|c}
\hline \multicolumn{2}{c|}{ Extraction methods } & TPC & TF & CT & HT & AOA \\
\hline \multirow{2}{*}{ ASE } & RM & $232 \pm 5$ & $15 \pm 2$ & $9.3 \pm 0.8$ & $435 \pm 10$ & $74 \pm 2$ \\
\cline { 2 - 7 } & DIC2 & $299 \pm 10$ & $23 \pm 2$ & $11.1 \pm 0.9$ & $560 \pm 10$ & $81 \pm 2$ \\
\hline \multirow{2}{*}{ SE } & RM & $201 \pm 5$ & $10 \pm 1$ & $4.2 \pm 0.3$ & $407 \pm 11$ & $72 \pm 2$ \\
\cline { 2 - 7 } & DIC2 & $225.66 \pm 5.0$ & $13 \pm 1$ & $7.0 \pm 0.5$ & $511 \pm 14$ & $76 \pm 1$ \\
\hline
\end{tabular}

TPC: Total Phenol Content(mg GAE/g db); TF: Total Flavonoids(mg cat.E/g db); CT: Condensed tannins(mg Querc.E/g db); HT: Hydrolysable tannins(mg TAE/g db); AOA: Anti-Oxidant Activity(Inhibition \%).

From the results summarized in Table 3, it is remarkable to note that flavonoids and condensed tannins proportions in the extracts constituted a small part of TPC. Several studies were shown that hydrolysable tannins contributed to total phenolics with significant amount in PoP[11].Moreover, our results on CT quantified from RM extracted by SE were in good agreement with the results of Saad et al.[56]vis-à-vis the characterization of PoP tannin extractives. The difference in performances between ASE and standard SE methods was clear as well as the positive effect of DIC-texturing. The 
highest scores for all responses were observed using ASE on DIC 2 sample compared to raw material. The obtained scores for DIC2 sample using ASE increases by 33\%, 74\%, 57\%, 10\% and $7 \%$ respectively for TPC, TF, CT, HT and\% inhibition in comparison with conventional extraction. Moreover, in SE of bioactive molecules of raw material without DIC texturing had the lowest yields. The increment of all bioactive molecules yields obtained by ASE in comparison to standard SE could be attributed to the positive effect of porosity and possible cell wall rupture induced by DIC. The effect of high pressure of ASE was much more important for DIC-swelled PoP thanks to higher penetration capability of methanol into pores and greater extractability of active molecules. Thus, DIC-assisted ASE greatly enhances the extraction yields.

\section{Correlations}

Results issued from the experiments showed that the higher the total phenol content, the better the antioxidant activity. In fact, it had been reported that the antioxidant activity of plant materials may be well correlated with the content of phenolic compounds [57].
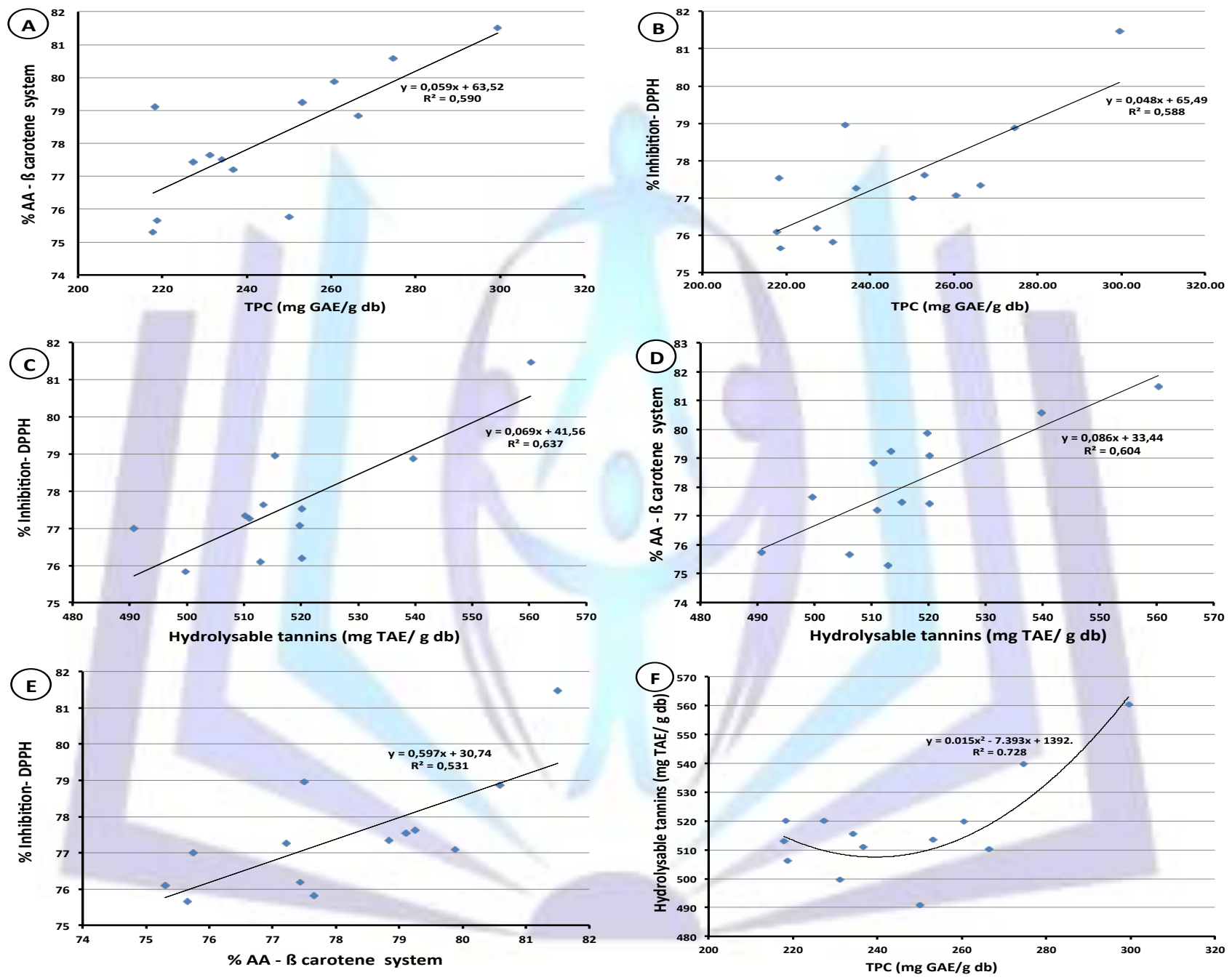

Figure11. Correlation curves: A) \% AA using B carotene systemvsTPC; B) inhibition \%using DPPH vs TPC; C)\% Inhibition using DPPH vs HT; D) \% AA using B carotene system vs HT; E) \% inhibition-DPPH vs \% AA using $B$ carotene system; F) Hydrolysable tannins vs TPC.

In the present study, significant correlations were found between TPC and AOA (DPPH, $\mathrm{R}^{2}=0.59$ (Figure $\left.11-\mathrm{A}\right)$ and $B$ carotene system, $\mathrm{R}^{2}=0.59$ (Figure 11-B)). Hydrolysable tannins correlated mostly with the antioxidant capacity (DPPH, $R^{2}=0.64$ (Figure 11-C) and $B$ carotene system, $R^{2}=0.6$ (Figure 11-D). These findings indicate that HT and TPC of PoP are major sources of natural antioxidant activity followed by flavonoids and condensed tannins. Hydrolysable tannins HT of Punicagranatum $L$. peel extract were excellent antioxidant compounds. This should be due to the fact that they are highly reactive as hydrogen and electron donors. Also, it was shown that PoP presented 2.8-fold higher antioxidant activity compared to pomegranate seeds and leaf extracts [6-1].Besides, the amount of HT from PoP extracts was higher than TPC but they correlated together $\left(R^{2}=0.73\right)$ (Figure 11-E and F). These results corroborated those of Saad et al.[56] but they were on contrast with those of Mustapha[11].Table 4 shows TPC and HT values estimated from these two situations. Their variations could be explained by the pomegranate cultivar variation as well as the extraction method also to the two different standards used in the calibration curves which were Gallic and Tannic acids. Our results showed a positive 
significant correlation between TPC and HT of the extracts, thus indicating that HTwere the major contributors to phenolic compounds which are responsible to the antioxidant activity.

Table4.Findings of Mustapha and Saad on their pomegranate peels PoP.

\begin{tabular}{c|c|c|c}
\hline Extraction method & $\begin{array}{c}\text { TPC }(\mathrm{mg} \mathrm{TAE} / \mathrm{g} \mathrm{db})^{\mathrm{a}} \\
\text { TPC }(\mathrm{mg} \mathrm{GAE} / \mathrm{gdb})^{\mathrm{b}}\end{array}$ & $\begin{array}{c}\text { Hydrolysable } \\
\text { tannins }(\mathrm{mgTAE} / \mathrm{g} \mathrm{db})\end{array}$ & References \\
\hline ASE water extraction & $264.3 \pm 14.7^{\mathrm{a}}$ & $262.7 \pm 11.5$ & {$[11]$} \\
\hline Magnetic stirring methanol soxhelt & $166.6 \pm 45.9^{\mathrm{b}}$ & $496.6 \pm 38.0$ & {$[56]$} \\
\hline
\end{tabular}

\section{Microscopy observation}

As reported in several studies, DIC treatment can modify the plant structure with controlled levels depending on the operating parameters. So, to study the microstructure changes after a DIC treatment, DIC-textured and untreated raw material RM peels were observed by SEM. The structural changes including external and internal microstructures are shown in Figure12. The structure of raw peels was more compact than DIC treated samples.

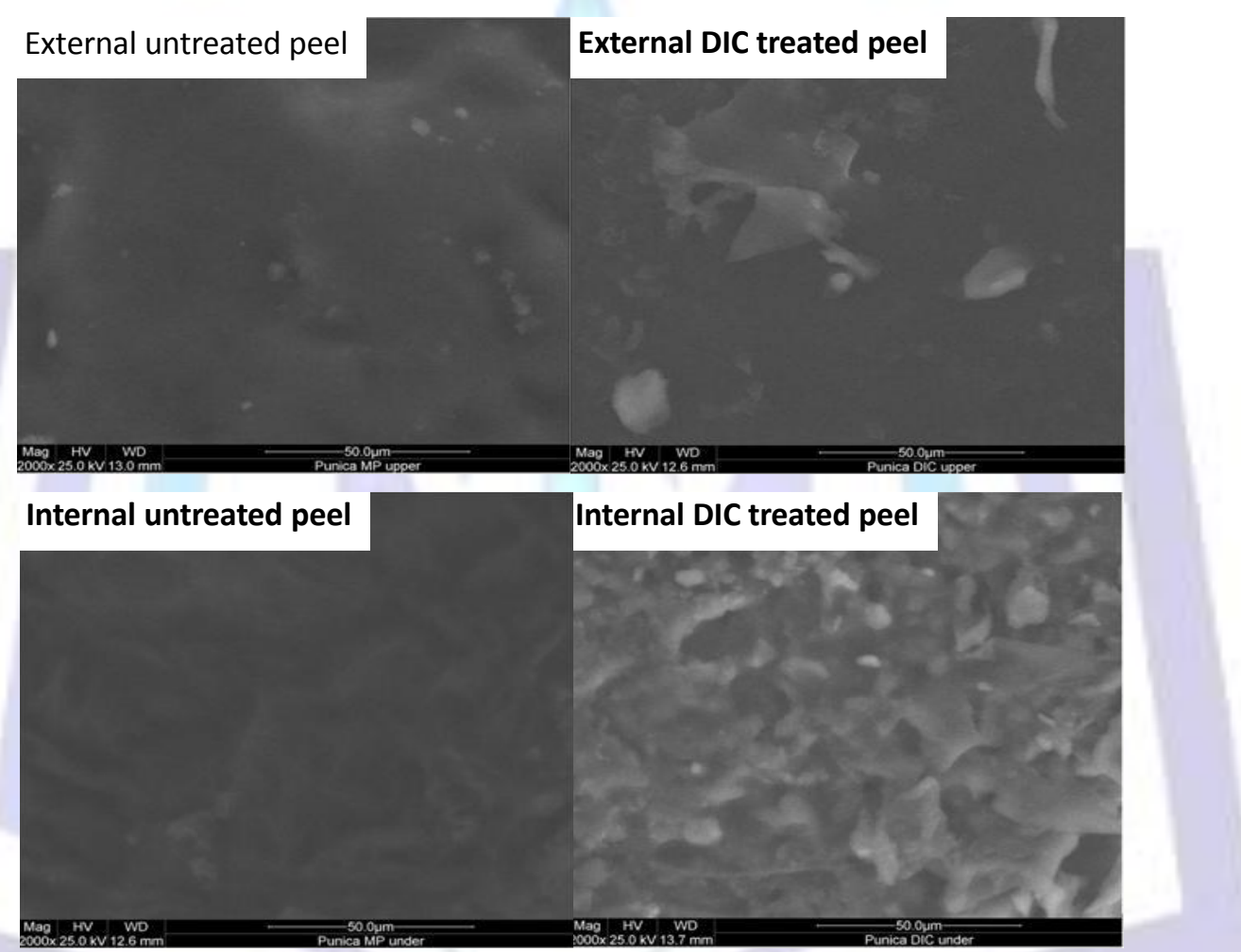

Figure13. SEM microstructure of internal and external microstructure of untreated and DIC treated peels of Punicagranatitum L.

In the latter figures, the dark regions were dominated and only some small holes appear. While, well-defined pores with a diameter of about $50 \mu \mathrm{m}$ were created by DIC treatment as shown in Figure12.By comparing the structures of DIC treated and the untreated peels, one notes that internal and external microstructures of DIC treated samples have more cavities and pores showing evident expansion of the structure.

These figures show the great impact of DIC on PoP microstructure. The generated structure modifications (porosity, specific surface area, etc.) should greatly modify functional characteristics. It would be then possible to control technological ability as a relevant way to greatly intensify mass transfer phenomena by improving diffusivity and permeability within the plant. It is also possible to increase the availability and/or the initial accessibility of some high added-value compounds. By the way, we may easily explain why the extraction is much better after DIC treatment.

\section{Effect of DIC as texturing pretreatment on extraction kinetics}

\section{Fundamental}

In solid -liquid extraction, mass transfer is hindered and limited by the interstitial structure and the cell walls of the matrix. Therefore, the solvent extraction process involves solid-liquid or liquid-liquid interactions in order to dissolve the desired components. Solid-liquid extraction is achieved by close contact between the solid and the solvent. During the extraction, 
the concentration of solute in the solid varies continuously, which explains the non stationary mass transfer. Globally, the operation starts with a superficial solute solubilization in solvent (washing stage). This occurs at the surface (external process) and has to be immediately transported within the surrounding solvent medium.

After this first stage, we should note the presence of a series of successive processes, which take place and reflect the interaction between the solid initially containing the solute and the solvent provoking the separation. These successive processes include (Allaf et Allaf, 2014 [29]; Elaydi et al., 2015 [58]):

- Solvent diffusion within the solid matrix

- Internal solute solubilization in the solvent; this occurs within the solvent, which has diffused within the porous solid plant matrix (internal process)

- Solute diffusion in the solvent within the solid matrix toward the surface

- External diffusion and/or mass convection transfer of the solute from the surface of the solid to the external environment

When mass transfer achieved through internal diffusion is the limiting process, Instant controlled pressure drop (DIC) can systematically contribute and define an intensified operation. The expanded structure induced by DIC is normally very effective in terms of both superficial washing and internal diffusion. Thus, the Coupled Washing/Diffusion CWD phenomenological model is defined.Once the material granule is solvent logged, the extraction process begins by a starting fast extraction step. Allaf [29] defined this starting step as the washing stage of the surface-solvent interaction. Subsequently, process involves solvent within the structure and the solute-in-solventdiffusion phenomena. The solute dissolved in the solvent is transported within the porous medium by Fick's type model. The solute transfer driving force is the gradient of apparent density ratio of solute to solid, with an effective diffusivity $D_{\text {eff }}\left(m^{2} s^{-1}\right)$ as the process coefficient [29-58-59].

$$
\frac{\rho_{\text {solute }}}{\rho_{d}}\left(\vec{v}_{\text {solute }}-\vec{v}_{d}\right)=-D_{\text {eff }} \vec{\nabla}\left(\frac{\rho_{\text {solute }}}{\rho_{d}}\right) \quad \text { Eq. } 10
$$

Where $\rho_{\text {solute }}$ is the apparent density of the solute within the solid matrix $\left(\mathrm{kg} \mathrm{m}^{-3}\right), \rho_{d}$ is the apparent density $\left(\mathrm{kg} \mathrm{m}^{-3}\right)$ of the solid (dry material), $\vec{v}_{\text {solute }}$ and $\vec{v}_{d}\left(\mathrm{~m} \mathrm{~s}^{-1}\right)$ are the absolute velocities of the solute and the solid dry material, respectively and $D_{\text {eff }}\left(\mathrm{m}^{2} \mathrm{~s}^{-1}\right)$ is the effective diffusivity of solute within the solid medium.By neglecting the possible shrinkage or swelling process, one can assume that $\rho_{d}=$ constant and $\vec{v}_{d}=0$ and has:

$$
\left(\rho_{\text {solute }} \vec{v}_{\text {solute }}\right)=-D_{\text {eff }} \vec{\nabla} \rho_{\text {solute }}
$$

By including continuity, it becomes

$$
\frac{\partial \rho_{\text {solute }}}{\partial t}=-\vec{\nabla}\left(D_{\text {eff }} \cdot \vec{\nabla} \rho_{\text {solute }}\right)
$$

Using the mass balance, we obtain the second Fick mass transfer law:

$$
\frac{\partial \rho_{\text {solute }}}{\partial t}=-D_{\text {eff }} \cdot \nabla^{2} \rho_{\text {solute }}
$$

Where tis the time. Further, for one direction radial flow, it becomes.

$$
\frac{\partial \rho_{\text {solute }}}{\partial t}=-D_{\text {eff }} \cdot \frac{\mathrm{d}^{2} \rho_{\text {solute }}}{\mathrm{dr}^{2}}
$$

The time $t$ of this diffusion stage should be considered after the washing stage timet $t_{0}$. The solutions required for this diffusion equation, such as the standard Crank's solutions, are highly dependent on the initial conditions and the geometry of the products [60]. Allaf and Allaf [29] adopted the classical Crank's solution for a spherical shape with a radius dpas follows:

$$
\frac{X_{\infty}-X}{X_{\infty}-X_{t_{o}}}=\sum_{i=1}^{\infty} \frac{6}{i^{2} \pi^{2}} \exp \left(-\frac{i^{2} \pi^{2} D_{e f f}}{d_{p}{ }^{2}}\left(t-t_{o}\right)\right)
$$

Where: $d_{p}$ is the average radius, $X$ is the amount of solute extracted at time $t, X_{\infty}$ is the amount of solute extracted at timet $\rightarrow \infty$ (Total yields), $X_{t o}$ is the amount of solute extracted at the starting diffusion time (t), it is chosen as a time for which the starting washing step has completely disappeared and the diffusion process is assumed to be the highest resistance of the solvent extraction[59].

Limited to its $1^{\text {st }}$ term, the logarithmic presentation would be assumed to be linear versus time (Eq. 16 and Eq. 17): 


$$
\begin{array}{ll}
\frac{X_{\infty}-X}{X_{\infty}-X_{t_{o}}}=A \exp \left(-k\left(t-t_{0}\right)\right. & \text { Eq. } 16 \\
\operatorname{Ln}\left(\frac{\mathrm{X}_{\infty}-\mathrm{X}}{\mathrm{X}_{\infty}-\mathrm{X}_{\mathrm{t}_{\mathrm{o}}}}\right)=-\mathrm{k}\left(\mathrm{t}-\mathrm{t}_{\mathrm{o}}\right) & \text { Eq. } 17
\end{array}
$$

This equationmay be transformed into a straight line with a slope $k$ from which $D_{e f f}$ could bedetermined:

$$
D_{e f f}=k \frac{d_{p}{ }^{2}}{\pi^{2}} \quad \text { Eq. } 18
$$

Crank polynomial expression is usually used to determine $D_{\text {eff }}$; in our cases, it was possible to limit it to its first term and standard Crank's solutions should only concern the time $\mathrm{t}>$ to. The starting accessibility $\delta X_{S}$ is then calculated by extrapolating the diffusion model to $\mathrm{t}=0 ; X_{\mathrm{o}} \neq\left(X_{\mathrm{i}}=0\right)$ :

$$
\delta X_{s}=X_{\mathrm{o}}-X_{\mathrm{i}}=X_{\mathrm{o}} \quad \text { Eq. } 19
$$

\section{CWD parameters: Effective diffusivity $D_{\text {eff }}$ and starting accessibility $\delta X_{s}$}

The experimental data adjusted with fundamental analysis and phenomenological modeling of kinetics of dynamic solvent extraction enable the quantification of the "washing" and "diffusion" steps, which are illustrated through "starting accessibility $\delta X_{s}$ " and "effective diffusivity $D_{\text {eff }}$ ", respectively. In order to obtain a thorough kinetics analyses, calculation of other parameters such as infinite yields $X_{\infty}$ and time to reach $80 \%$ of final extraction $t_{80 \%}$ was performed. ASE results were used in this study kinetics as giving $X_{\infty}$. The kinetics were obtained for both raw material and DIC-textured samples of Punicagranatum $L$ peels through dynamic methanol extraction with high magnetic stirring. Figure 13reveals some examples of typical kinetics of TPC extraction at $40^{\circ} \mathrm{C}$ from both Raw Material and DIC treated samples.
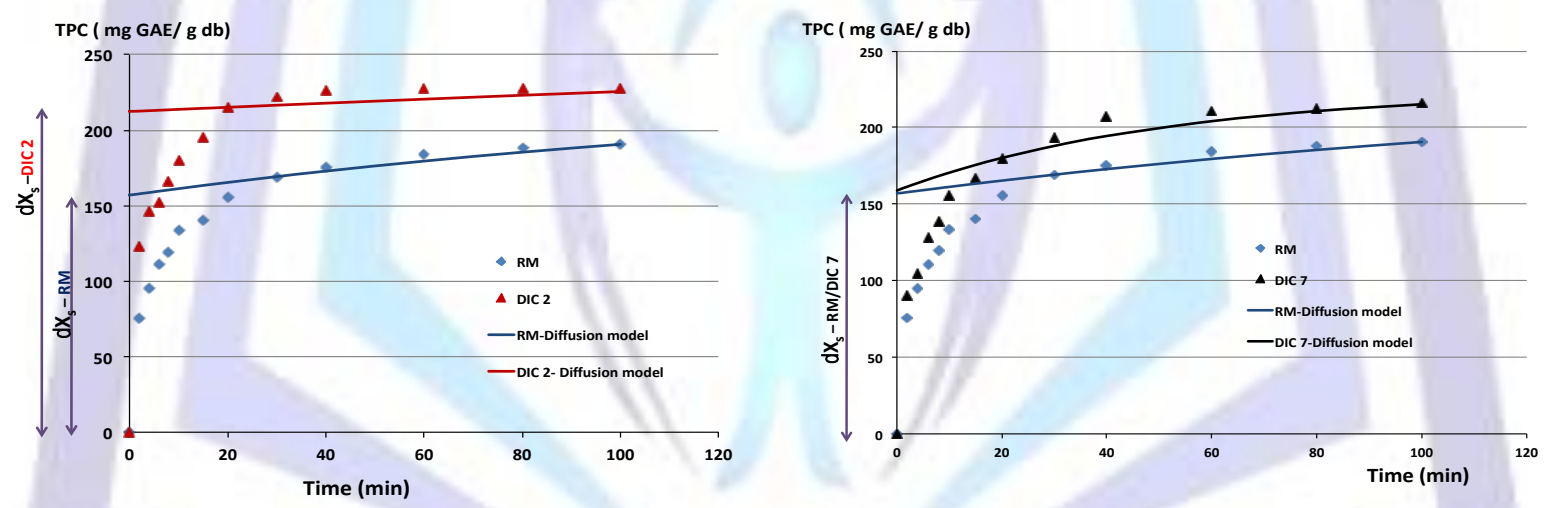

Figure13.Typical kinetics of methanol extraction of TPC at $40{ }^{\circ} \mathrm{C}$ from Raw Material and DIC treated samples:

Phenomenological model of surface interaction (washing revealed by the starting accessibility $\delta X_{s}$ and internal diffusion stages.

It was noted that, under some specific conditions of pressure and time, DIC treatment allows TPC yields in 100 min to be higher than the raw material infinite yields. As mentioned in Figure 14, DIC allowed an improvement of $129 \%$.

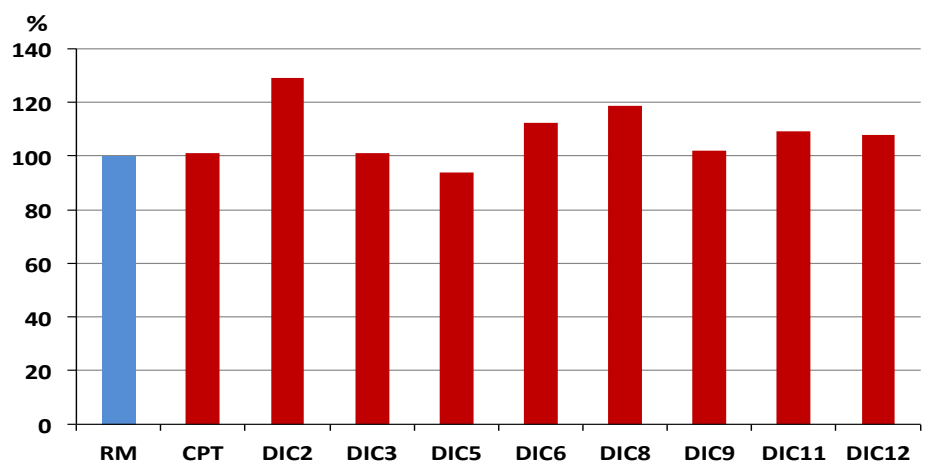

Figure 14.Improvement of yields on TPC methanol extraction at $40{ }^{\circ} \mathrm{C}$ based on Raw Material. CPT: Centralized Point Treatment 
Table 5 summarizes the results of the major responses $\left(X_{\infty}, D_{\text {eff }}, \delta X_{s}\right.$ andt $\left.t_{80 \%}\right)$ which show the effect of DIC-assisted dynamic extraction process. Moreover, the high value of $\mathrm{R}^{2}$ as regression coefficient highlights the high ability of the phenomenological CWD model to fit the experimental study. These response values greatly depend on the operating DIC parameters ( $\mathrm{P}$ and $\mathrm{t})$.Thesignificance of such parameters is to justify, if the histogram, in Pareto chart, crosses the front of significance, translating the threshold at $5 \%$.

Table 5. Experimental data of the composite central design and the results of TPC yield after 100 min of dynamic methanol extraction at $40 \stackrel{\circ}{ } \mathrm{C}$.

\begin{tabular}{c|c|c|c|c|c}
\hline \multirow{2}{*}{ Run $\mathrm{n}^{\circ}$} & \multirow{2}{*}{$\mathrm{R}^{2}$} & $\boldsymbol{X}_{\infty}$ & $\boldsymbol{\delta} \boldsymbol{X}_{\boldsymbol{s}}$ & $D_{\text {eff }}$ & $\mathrm{t}_{80 \%}$ \\
\cline { 3 - 6 } & & \multicolumn{2}{|c|}{$\mathrm{mg} \mathrm{GAE} / \mathrm{g} \mathrm{db}$} & $10^{-10} \mathrm{~m}^{2} \mathrm{~s}^{-1}$ & $\mathrm{~min}$ \\
\hline RM & 0.941 & $232 \pm 5$ & 156.93 & 0.47 & 156 \\
\hline CPT & $0.815 \pm 0.12$ & $232 \pm 6$ & $159.72 \pm 7$ & $2.59 \pm 0.4$ & $61 \pm 6$ \\
\hline DIC2 & 0.609 & $299 \pm 10$ & 212.32 & 0.27 & 310 \\
\hline DIC3 & 0.979 & $234 \pm 4$ & 95.71 & 8.22 & 18 \\
\hline DIC5 & 0.769 & $218 \pm 9$ & 129.00 & 1.39 & 133 \\
\hline DIC6 & 0.844 & $261 \pm 9$ & 135.20 & 1.27 & 100 \\
\hline DIC8 & 0.709 & $275 \pm 7$ & 165.58 & 0.98 & 105 \\
\hline DIC9 & 0.885 & $237 \pm 6$ & 152.65 & 3.22 & 45 \\
\hline DIC11 & 0.941 & $253 \pm 10$ & 149.51 & 1.37 & 89 \\
\hline DIC12 & 0.842 & $250 \pm 10$ & 163.29 & 1.85 & 69 \\
\hline
\end{tabular}

$t_{80 \%}:$ time in min to get $80 \%$ of final extraction

The improvements on TPC yields allowed us to choose $X_{\infty}$ from ASE and not from dynamic maceration.DIC $X_{\infty}$ and $\mathrm{RM} X_{\infty}$ yields are the same values given in Table 2. RSM statistical analyses show the significance effects of DIC operating parameters as shown in Figure 4.

The effective diffusivity values were determined using the method of slopes by plotting experimental data of $\operatorname{Ln}\left(\frac{x_{\infty}-X}{x_{\infty}-X_{t_{0}}}\right)$ versus extraction time $t$, while excluding the experimental values close to the initial time $(t=0)$. The effective diffusivity $D_{e f f}$ was calculated from the values of $k$ (Eq. 18). Table5 shows the results of $D_{e f f}$ in the case of TPC extraction kinetics based on CWD model. These values from various DIC samples excluding DIC 2 were ranged from 0.98 to 8.22 $10^{-10} \mathrm{~m}^{2} \mathrm{~s}^{-1}$, which are twice to seventeentimes higher than the effective diffusivity of the raw material $\left(0.4710^{-10} \mathrm{~m}^{2} \mathrm{~s}\right.$ $\left.{ }^{1}\right)$. These findings can be attributed to the positive effect given by DIC process in modifying the plant structure, which greatly facilitates mass diffusion. DIC expansion systematically enabled PoP to be much more adapted to mass transfer.

The statistical treatment of results was carried out and Pareto, general trends, response surface, empirical model coefficients, $\mathrm{R}^{2}$ and optimal treatment conditions were determined using software for Windows (Figure 15). The regression models of $D_{e f f}$ is carried out with $\mathrm{R}^{2}=80 \%$ :

$$
D_{\text {eff }}=-7.58+82.43 P-0.494 t-98.19 P^{2}-0.688 P t+0.019 t^{2} \quad \text { Eq. } 20
$$

The model allows optimizing $D_{\text {eff }}$ at $\mathrm{P}=0.3 \mathrm{MPa}$ steam pressure and $\mathrm{t}=35 \mathrm{~s}$ thermal treatment time. Its value was 6.71 against $0.4710^{-10} \mathrm{~m}^{2} \mathrm{~s}^{-1}$ for RM. 

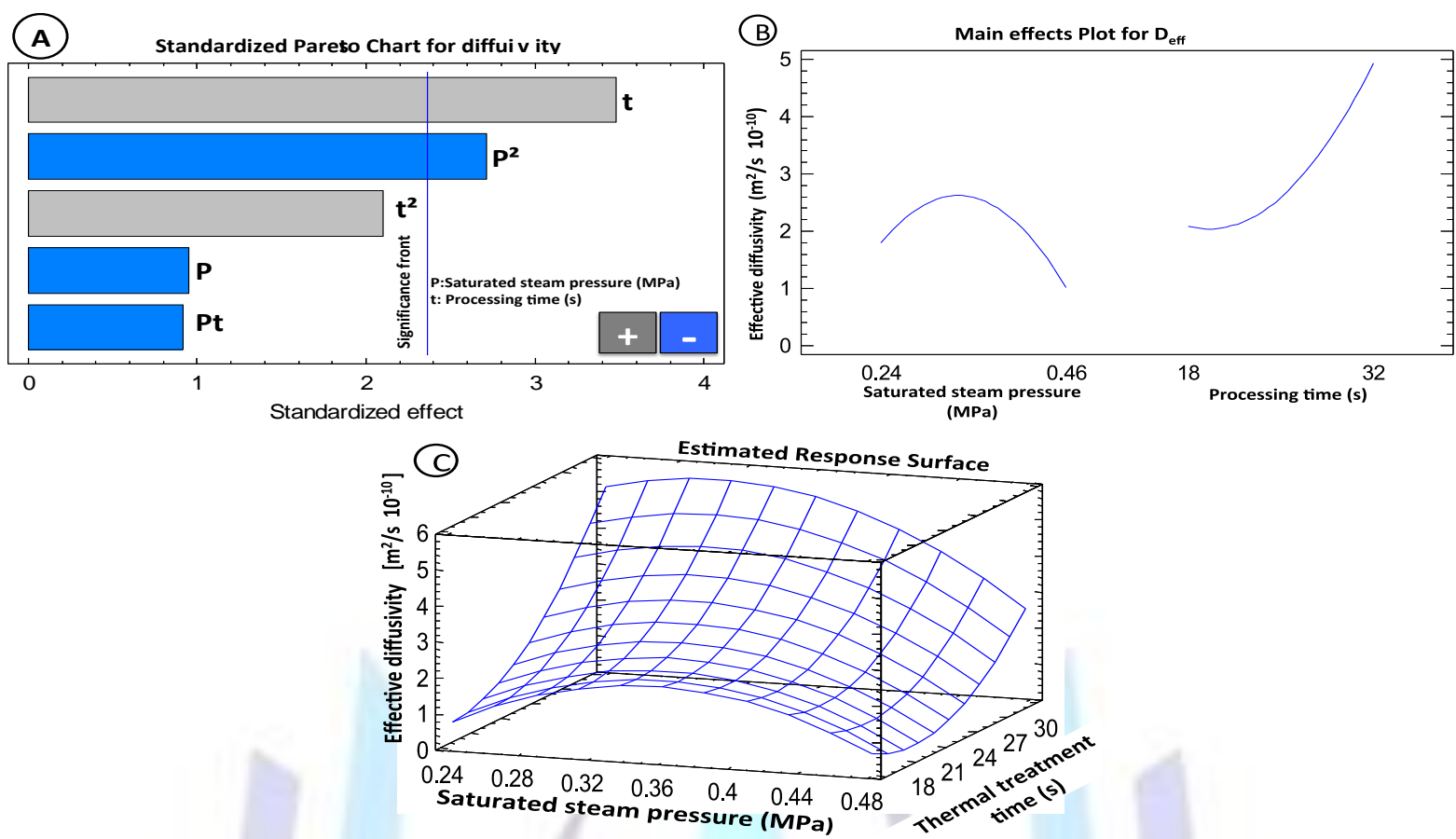

Figure 15. Effective diffusivity $D_{e f f}$ of TPC extraction kinetics versus DIC operating parameters:(A)Pareto chart, (B)general trends, and (C) response surface.

Solute extraction from the surface can be revealed through the Starting accessibility $\delta X_{s}$ parameter done in Eq. 19. Pareto chart (Figure 16) shows the non-significance effect of $\mathrm{P}$ and $\mathrm{t}$ on $\delta X_{s}$. These results can be explained by the complexity of PoP structural morphology, which contains an interior network of membranes. However, DIC expansion created at both external and internal peel surfaces should result in theformation of pores inside the solid matrix and the improvement in starting accessibility. Therefore, an improvement of starting accessibility achieved $135 \%$ using DIC2 treatment.

The time for getting $80 \%$ of the final extraction of TPCt ${ }_{80 \%}$ was around $156 \mathrm{~min}$ for RM, and skyrocketed to $18 \mathrm{~min}$ for DIC 3 under a $\mathrm{P}=0.35 \mathrm{MPa}$ and $\mathrm{t}=35 \mathrm{~s}$. Therefore, DIC treatment dramatically decreased $\mathrm{t}_{80} \%$ for TPC extraction. DICtexturing results in great accelerating in TPC extraction kinetics.

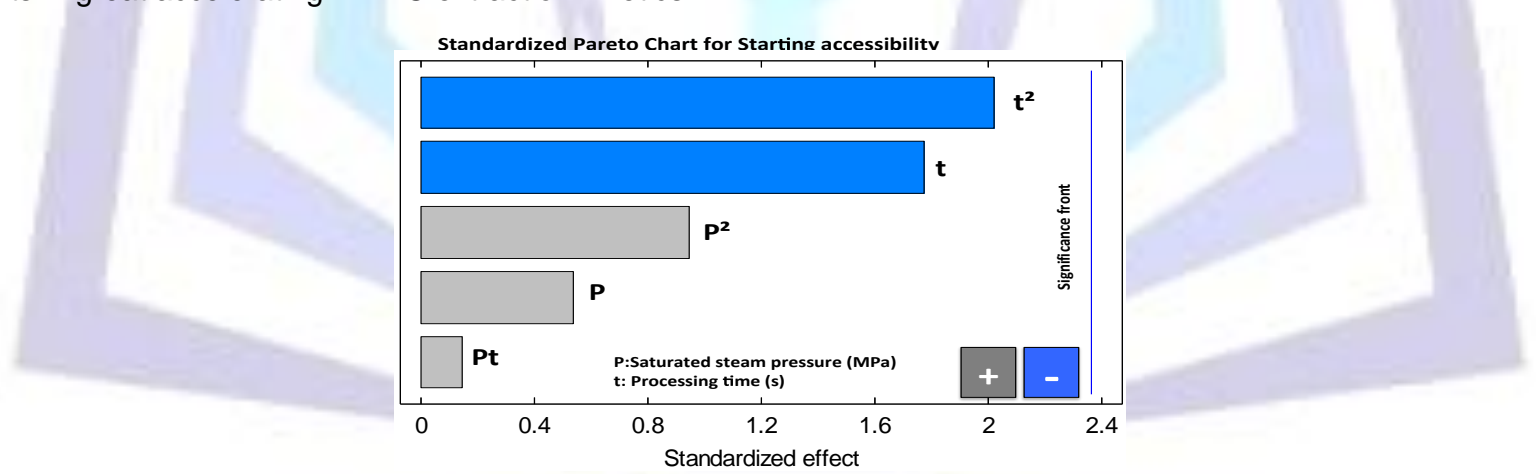

Figure 16. Pareto chart of DIC operating parameters for starting accessibility $\delta X_{s}$ of TPC extraction kinetics.

In general trends, all results obtained on the entire study through different DIC treatments proved that the raw material completely leached still contained residual amounts of bioactive molecules previously inaccessible. The mechanical impact on the instantaneous drop to a vacuum resulted in an expansion of PoP matrix, which implies increasing in porosity and improves the diffusivity of the solvent within the plant as proved by different studies [61-28].It also could implysome disruption of cell walls, thus increasing the extraction availability of phenolic and other active compounds. Therefore, the amount of bioactive compounds in the solid matrix becomes more available and the extractability of these molecules easier. DIC technology seems to be a good option for intensifying extraction of bioactive molecules from PoP.It also offers a promising alternative to conventional and some new extraction methods.

However more studies are needed to determine the effect of DIC treatment on PoP bioactive molecules propreties. 


\section{Comparative study on the energy consumption between conventional and innovative extraction (DIC extraction) methods}

The characteristics of washing and diffusion steps in the extraction can be determined by the proportion of broken and intact cells after sample preparation, e.g. grinding. So, after the first intensification of the extraction parameters including particule size, solvent polarity and concentration, temperature and time extraction..., the second intensification included the select of the acting methods on the solid matrix to achieve the shortkinetic that is means the low energy consumption and the good quality and quantity yields of the extractable bioactive compounds. The conventional extraction methods such as maceration and soxhlet extraction have shown low efficiency and potential environmental pollution due to large volumes of organic solvent used and long extraction time required in those methods [21] The solid -liquid reflux extractions can last from 12 to 24 hours. The maceration is an operation that involves soaking a solid matrix in a liquid or in a wetland in order to extractsome active nutrients. This operation is usually long and often give a mediocre performance can last from 4 to about 10 days.

A number of methods have been developed in recent years such as microwave, ultrasound-assisted extractions, and techniques based on use of compressed fluids as extracting agents, such as pressurized fluid extraction (PFE) or accelerated solvent extraction (ASE) were also applied in the extraction of phenolic compounds from plant materials. Improvement of the extraction kinetics can also be achieved using advanced pretreatment such instant controlled pressure drop (DIC). DIC pretreatment method fragments the sample forming microspores as it is decompressed through sudden release of high steam pressure. This improves the washing step of the extraction and enhances the diffusion of the solute into the solvent [23]Various industrial applications haveshown that DIC provides both a high product quality and appropriate process performances, thus saving energy and preserving the environment (green process) [29]. In the extraction of essential oil, the DIC process is a direct extraction-separation technique, which is not like the molecular diffusion in conventional techniques. It allows volatile compounds to be removed by both evaporation for a short time at high temperature $\left(180^{\circ} \mathrm{C}\right)$ and high pressure $(10 \mathrm{bar})$ and auto-vaporization from alveolated plant structures resulting from multi-cycle instantaneous pressure drop [29]. This solvent-free process presents a significant improvement whether in efficiency or in energy consumption and a very short heating time in each DIC cycle eliminate the thermal degradation. Moreover, the DIC obtained the same or even higher yield of essential oil with a higher quality than conventional methods regarding to their more oxygenated compounds and lower sesquiterpene hydrocarbons. In addition, heating time and cycle number in particular, have an influence on the extraction efficiency of DIC for all aromatic herbs and spices [25].

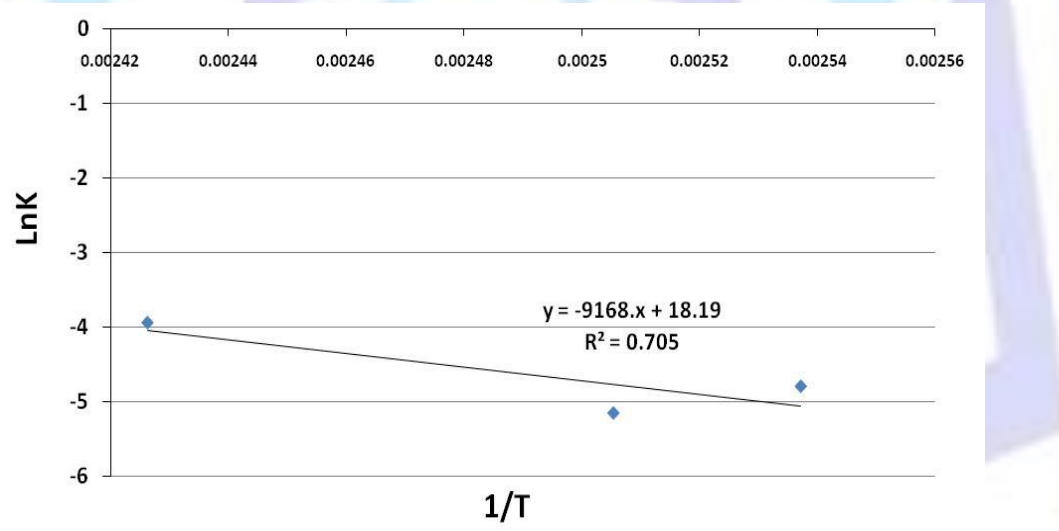

Figure17. DIC energy calculation: $L n k=f(1 / T)$.

In this paper, the DIC process was pursued as a post harvesting treatment to improve yield, and produce higher quality of the final products with an 'instant' processing time and minimum processing energy requirements. We are able to quantify the activation energy $E_{a}$ from the phenomenological model for some points found in the experimental design. The trials (DIC 8, DIC11and the five central points (CP) have the same treatment time $\mathrm{t}=25 \mathrm{~s}$ but different saturated steam pressure (P) which means different temperatures (Table 2). The presentation ofk $\left(\mathrm{s}^{-1}\right)$ versus $1 / \mathrm{T}$ (where $\mathrm{T}$ is the temperature expressed in Kelvin (K)) must lead to a straight line of slope equal to $E_{a} / R$ (with $R$ the universal gas constant value) (Figure 17). The quantified activation energy according to the phenomenological model of the kinetics of TPC extraction is equal to $13.13 \mathrm{~kJ}_{\mathrm{mol}} \mathrm{m}^{-1}$. This value remains low.

\section{CONCLUSION}

The present work discloses a method for recovering bioactive molecules from a natural source of Punicagranatum $L$ peels, which is a waste, by-product of juice, using a high temperature-short time thermo mechanical process; Instant Controlled Pressure Drop (DIC). DIC-texturing can improve the extraction yields of Total phenols content, Total flavonoids, condensed tannins, and hydrolysable tannins and improve antioxidant properties of ASE extracts. The highest yields and antioxidant activity were obtained by coupling both DIC and ASE treatments. Significant correlations were found between TPC and AOA. Hydrolysable tannins correlated mostly with the antioxidant capacity. These findings indicate that hydrolysable tannins and phenolic from pomegranate peels PoP were major sources of natural antioxidants followed by flavonoids and condensed tannins. 
The impact of DIC on microstructure delivered a reliable explanation regarding our results. The swelling and expansion of the cells enabled a better kinetic extraction in terms of diffusivity and starting accessibility, as well as availability of such bioactive molecules.

\section{REFERENCES}

[1] T. Ismail, P. Sestili, and S. Akhtar, "Pomegranate peel and fruit extracts: A review of potential anti-inflammatory and antiinfective effects", Journal of Ethno pharmacology, vol. 143, no. 2, pp.397-405, 2012.

[2] E. P. Lansky and R. A. Newman, "Punicagranatum (pomegranate) and its potential for prevention and treatment of inflammation and cancer", Journal of Ethnopharmacology, vol. 109, no. 2, pp.177-206, 2007.

[3] P. Zhongli, Q. Wenjuan, M. Haile, G.Griffiths, and T. H. McHugh, "Continuous and pulsed ultrasound-assisted extractions of antioxidants from pomegranate peel”, UltrasonicsSonochemistry, vol. 18, no. 5, pp.1249-1259, 2012.

[4] Q.Wenjuan, P. Zhongli, andM. Haile, "Extraction modeling and activities of antioxidants from pomegranate marc"Journal of Food Engineering, vol. 99, no. 1, pp.16-23, 2010

[5] F.Afaq, M.Saleem, C.G. Krueger, J.D. Reed, and H.Mukhtar, “Anthocyanin and hydrolysable tannin-rich pomegranate fruit extract modulates MAPK and NF-kappaB pathways and inhibits skin tumorigenesis in CD-1 mice", Int. J. Cancer, vol. 113, no. 3, pp. 423-433, 2005.

[6] P. S.Negi, G. K. Jayaprakasha, and B. S. Jena, "Antioxidant and antimutagenicactivities of pomegranate peel extracts", Food Chemistry, vol. 80, no. 3, pp. 393-397, 2003.

[7] B. Naveena, A. Sen, R. Kingsly, D. Singh, and N. Kondaiah, "Antioxidant activity of pomegranate rind powder extract in cooked chicken patties", Interna-tional Journal of Food Science and Technology, vol. 43, no. 10, pp. 1807-1812, 2008.

[8] S.A.R. Amani, G. Edwards, M. Al-Sibani, G.Al-Thani, A. S. Al-Harrasi, and M.S. Rahman, "Phenolic Constituents of Pomegranate Peels (Punicagranatum L.) Cultivated in Oman”, European Journal of Medi-cinal Plant, vol. 4, no.3, pp. 315-331, 2014.

[9] H.O.Hakime, Y. Hulya, and S. S. Isbilir, "Comparison of antioxidant activities of Juice, peel, and seed of pomegranate (Punicagranatum L.)and interrelation-ships with total phenolic, tannin, anthocyanin, and flavonoid contents", Food Sci. Biotechnol, vol. 21, no. 2, pp. 373-387, 2012.

[10] Y. Li, C.Guo, J.Yang, J.Wei, J. Xu, andS. Cheng, "Evaluation of antioxidantproperties of pomegranate peel extract in comparison with pomegranate pulpextract”, Food Chemistry, vol. 96, no. 2, pp. 254-260, 2006.

[11] C.Mustafa and H. Yasar, "Pressurised water extraction of polyphenols from pomegranate peels", Food Chemistry, vol. 123, no. 3, pp.878-885, 2010.

[12] A. Adeel, I.A. Ali ShaukatBhatti, F. Zsila, "Dyeing of cotton fabric usingpomegranate (Punicagranatum) aqueous extract", Asian J. Chem., vol.21, no. 3, pp. 3493-3499, 2009.

[13] A. Srivastava and R.Sinha, D. Roy, “Toxicological effects of Malachite Green”, Aquat.Toxicol, vol. 66, no. 3, pp. 319-329, 2004.

[14] T.S. Najim and S.A. Yassin, "Removal of Cr (VI) from aqueous solution using modifiedpomegranate peel: equilibrium and kinetic studies", E-J. Chem. vol. 6, no. S1, pp. S129-S142, 2009.

[15] V. S. P. Chaturvedula and I. Prakash, "Bioactive Chemical constituents from pomegranate (Punicagranatum) juice, Seed and Peel-A Review", International Journal of Research in Chemistry and Environment, vol. 1, no. 1, pp.1-18.

[16] Ç. Mustafa, C. Necattinand E. Fatma, "Pomegranate peelphenolics microencapsulation, storage, stability and potential ingredient for functional food development", Lebesmittel-Wissenschaftand technologie, vol. 55, no. 1, pp. 117-123, 2014.

[17] M. Elhem, B.K. Abdennaceur, H. Mansour, A. Mabrouka, B. Khouloud, and F. Ali, "Selection of pomegranate (Punicagranatum L.)in south-eastern Tunisia African”, Journal of Biotechnology, vol. 10, no. 46, pp. 9352-9361, 2011.

[18] M. Mars, "La culture du grenadier (Punicagranatum L.) et du figuier (Ficuscarica L.) en Tunisie "Underutilized fruit crops in the MediterraneanregionZaragoza : CIHEAM, Cahiers Options Méditerranéennes, no. 13, pp. 85-95, 1995.

[19] T. Reza, H. Elham, and B. Ali, "Optimization of ultrasonic-assisted extraction of pomegranate (Punicagranatum L.) peel antioxidants by response surface methodology", Separation and Purification Technology, vol.98, pp. 16-23, 2012.

[20] D.D. Bartnik, C.M. Mohler, M. Houlihan, “United states patent application, 20060088627”, April 27, 2006.

[21] D. Jin and J. M. Russell, "PlantPhenolics: Extraction, analysis and their antioxidant and anticancer properties", Molecules, vol. 15, no. 10, pp. 7313-7352, 2010.

[22] K. Abascal, L. Ganora, and E. Yarnell, "The effect of freeze-drying and its implications for botanical medicine: a review", Phytother. Res., vol. 19, no. 8, pp. 655-660, 2005.

[23] B. Ben Amor and K. Allaf, "Impactof texturing using instant pressure drop treatment prior to solvent extraction of anthocyanins from Malaysian Roselle (Hibiscus sabdariffa)", Food Chem., vol. 115, no.3, pp. 820-825, 2009.

[24] T. Allaf, S. Mounir, V. Tomao, andF. Chemat. Instant controlled pressure drop combined to ultrasounds as innovative extraction process combination: fundamental aspects. Procedia. Eng., vol.42, pp. 1061-1078, 2012.

[25] T. Allaf, V. Tomao, C. Besombes, and F. Chemat, "Thermaland mechanical intensification of essential oil extraction from orange peel via instant autovaporization”, Chemical Engineering and Processing, vol.72, pp.24-30, 2013. 
[26] K. Elaydi, I. Kamal, A. Bedoui, E. Elimam and K. Allaf, "Intensification of the Solvent Extraction of Rhustripartitumbioactive molecules using Instant Controlled Pressure Drop (DIC). British Journal of Applied Science \& Technology, vol. 4, no. 11, pp. 1576-1593, 2014.

[27] B. Ben Amor, L. Cécile, P. Andre, and K. Allaf, "Effect of instant controlled pressure drop treatments on the oligosaccharides extractability and microstructure of Tephrosiapurpurea seeds", J. Chromatogr. A, vol. 1213, no. 2, pp. 118-124, 2008.

[28] T. Allaf, V. Tomao, K.Ruiz, and F. Chemat, "Instant controlled pressure drop technology and ultrasound assisted extraction for sequential extraction of essential oil and antioxidants", UltrasonicsSono-chemistry, vol.20, no. 1, pp. 239-246, 2013.

[29] T.Allaf and K. Allaf, "Instant Controlled Pressure Drop (D.I.C.) in Food Processing”, Springer, New York, 2014.

[30] J. Haddad, R.Greiner, and K. Allaf, "Effect of instantaneous controlled pressure drop on the phytate content of lupin", LWT Food Science and Technology, vol. 40, no. 3, pp. 448-453, 2007.

[31] B. Berka-Zougali, A. Hassani, C. Besombes, and K. Allaf. "Extraction of essential oils from Algerian myrtle leaves using instant controlled pressure drop technology", Journal of Chromatography A, vol. 1217, no. 40, pp.6134-6142, 2010.

[32] P. Yasoubi, M. Barzegar, M.A. Sahari, M.H. Azizi, "Total phenolic contents and antioxidant activity of pomegranate (Punicagranatum L.)peelextracts. J. Agric. Sci. Technol., vol. 9, no. 9, pp. 35-42, 2007.

[33] K. B. Ajaikumar, M.Asheef, B.H.Babu, andJ.Padikkala, "The inhibitionofgastric mucosal injurybyPunicagranatum L. (pomegranate) methanolic extract", Journal ofEthnopharmacology, vol. 96, no. 1-2, pp. 171-176, 2005.

[34] S.Iqbal, S.Haleem, M.Akhtar, M. Zia-ul-Haq, and J.Akbar, "Efficiency of pomegranate peel extract in stabilization of sunflower oil under accelerated conditions", Food Research International, vol.41, no. 2, pp. 194-200, 2008.

[35] M.Zahin, F.Aqil, and I. Ahmad, "Broad spectrum antimutagenic activity of antioxidant active fraction of Punicagranatum L. peel extracts", Mutation Research, vol.703, no. 2, pp. 99-107, 2010.

[36] B. Lapornik, M. Prosek, and A.G. Wondra, "Comparison of extracts prepared from plant by-products using different solvent and extraction time”, J. Food. Eng., vo. 71, no. 2, pp. 214-222, 2005.

[37] C. C. Chang, M.H. Yang, H. M. Wen, andJ.CChern, "Estimation of total flavonoid content in propolis by two complementary colorimetric methods", Journal of food and Drugs Analysis, vol. 10, no. 3, pp. 178-182, 2002.

[38] W.Feucht and D. Treutter, "The role of flavan-3-ols and proanthocyanidins in plant defence, In:Inderjit S, DakshiniKMM, Foy CL (eds), Principles and practices in chemical ecology”, CRC Press, Boca Raton, pp. 307-338, 1999.

[39] P. Schofield, D.M. Mbugua, and A.N. Pell, “Analysis of condensed tannins: a review”, Anim. Feed Sci. Technol. vol. 91, no. 1-2, pp. 21-40, 2001.

[40] M. L Price, S.VScoyoc, andL. G Buttler, "A critical evaluation of the vanillin reaction as an assay for tannin in sorghum grain", J. Agric. Food Chem., vol. 26, no.5, pp. 1214, 1978.

[41] R. B. Willis and P. R. Allen, "Improved method for measuring hydrolysable tannins using potassium iodate", The Analyst, vol. 123, no. 3, pp. 435-439, 1998.

[42] W. Brand-Williams, M. E. Cuvelier, and C. Berset, "Use of free radical method to evaluate antioxidant activity", LWT-Food Science and Technology, vol. 28, no. 1, pp. 25-30, 1995.

[43] R. P. Singh, K. N. C. Murthy, and G. K. Jayaprakasha, "Studies on the antioxidantactivity of pomegranate (Punicagranatum) peel and seed extracts using in vitro models", Journal of Agricultural and Food Chemistry, vol.50, no. 1, pp. 81-86, 2002.

[44] S. Keka, D.S. Papita, and D. Siddhartha, "Response surface optimization and artificial neural network modeling of microwave assisted natural dye extraction from pomegranate rind", Industrial Crops and Products, vol.37, no. 1, pp.408-414, 2012.

[45] M.I. Gil, F.A.Tomas-Barberan, B.Hess-Pierce, D.M Holcroft, andA.A. Kader, "Antioxidant activity of pomegranate juice”, J. Agric. Food Chem., vol. 48, no. 10, pp. 4581-4589, 2000.

[46] M. Sriro, and S.S. Chen, "Flavour Fragrance J., 10, vol. 4, pp. 259-272, 1995.

[47] D. Cardon, Colorants et Tannins", vol. 3. Pays Bas. 2005.

[48] U. D. Chavan, F. Shahidi, and M.Naczk, "Extraction of condensed tannins from beach pea (Lathyrusmaritimus L.) as affected by different solvent”, Food Chem., vol. 75, no. 4, pp. 509-512, 2001.

[49] B. Ben Amor, and K. Allaf, "Maitrise de l'aptitudetechnologique de la matièrevégétaledans les opérationsd'extraction de principesactifs; texturation par Détente InstantanéeContrôlée DIC" Génie des ProcédésIndustriels. La Rochelle, Université de La Rochelle: 187, 2007.

[50] M. Jerez, S. Touriño, J. Sineiro, J.L.Torres, and M. J.Nuñez, "Procyanidins frompine bark: Relationships between structure, composition and antiradical activity", Food Chemistry, vol. 104, no.2, pp. 518-527, 2007

[51] B.N.Ames, M.K.Shigenaga, andT.M Hagen, “Oxidants, antioxidants, and the degenerative diseases of aging”, Proc. Natl. Acad. Sci. USA, vol, 90, no. 17, pp. 7915-7922, 1993.

[52] K. Erik, L. Vladimir, andC. Zuzana, "On the energetic of phenol antioxidants activity", Petroleum \& Coal, vol. 47, no.1, pp. $33-39,2005$.

[53] G. K.Jayaprakasha, R. P.Singh, andK. K.Sakariah, "Antioxidant activity of grape seed (Vitisvinifera) extracts on peroxidation models in vitro", Food Chemistry, vol. 73, no. 3, pp. 285-290, 2001. 
[54] B.Lillian, F. Maria-Joao, Q. Bruno, C.F.R.Isabel, and P. Baptista, "Total phenols, ascorbic acid, b-carotene and lycopene in Portuguese wild edible mushrooms and their antioxidant activities", Food Chemistry, vol. 103, no. 2, pp.413-419, 2007.

[55] N. Tokton, A. Ounaroon, P. Panichayupakaranant, and W. Tiyaboonchai, "Physical development of ellagic acid rich pomegranate peel extract loadednanostructured lipid carriers (nlcs)", International Journal of Pharmacy and Pharmaceutical Sciences, vol.6, no. 4, pp. 259-265. 2014.

[56] H. Saad, F. Charrier-El Bouhtoury, A. Pizzi, K. Rode, B. Charrier, and N. Ayed, "Characterization of pomegranate peels tannin extractives", Industrial Crops and Products, vol. 40, pp.239-246, 2012

[57] L.Lahouar, A. El Arema, F. Ghrairi, H. Chahdoura, H. Ben Salemc, Mouledi El Felah, and A."Phytochemical content and antioxidant properties of diverse varieties of whole barley (Hordeumvulgare L.) grown in Tunisia", Food Chemistry, vol. 145, pp. $578-583,2014$.

[58] E.khaoula, I.Kamal, A.Bedoui, and K. Allaf, "Innovative process of texturing-assisted solvent extraction: Impacts on polyphenols, flavonoids, tannins and antioxidant of Henna", International Journal of Emerging Technology and Advanced Engineering. vol. 5, no. 3, pp. 403-414, 2015.

[59] S.Mounir, T.Allaf, B.Berka, A. Hassani, K. Allaf, "Instant Controlled Pressure Drop technology: From a new fundamental approach of instantaneous transitory thermodynamics to large industrial applications on high performance-high controlled quality unit operations", C. R. Chimie, 2014.

[60] J. Crank, "The mathematics of diffusion", $2^{\text {nd }}$ edition, Clarendon Press, Oxford, 1975.

[61] B.B. Zougali, A. Hassani, C. Besombes, K. Allaf. "Extraction of essential oils from Algerian myrtle leaves using instant controlled pressure drop technology”, J. Chromatogr. A.vol. 1217, no. 40, pp. 6134-6142, 2010. 